SCHURMANN, Miguel “¿Es científico el discurso elaborado por la dogmática jurídica?

Una defensa de la pretensión de racionalidad del discurso dogmático elaborado por la ciencia del derecho penal".

Polít. crim. Vol. 14, № 27 (Julio 2019), Art. 16, pp. 549-598

[http://politcrim.com/wp-content/uploads/2019/06/Vol14N27A16.pdf]

\title{
¿Es científico el discurso elaborado por la dogmática jurídica? Una defensa de la pretensión de racionalidad del discurso dogmático elaborado por la ciencia del derecho penal $^{*}$
}

\section{Is the discourse developed by legal theory scientific? A defense of the rationality pretension of the dogmatic discourse elaborated by the science of criminal law}

\section{Ist der von der Rechtsdogmatik entwickelte Diskurs wissenschaftlich? Eine Verteidigung des Rationalitätsanspruchs des von der Strafrechtswissenschaft entwickelten dogmatischen Diskurses}

\author{
Miguel Schurmann Opazo (L.L.M. U. Bonn) \\ Profesor asistente del Departamento de Ciencias Penales, Universidad de Chile \\ miguelschurmann@gmail.com
}

\section{Resumen}

El artículo desarrolla una propuesta alternativa de análisis a la tradicional pregunta por el valor científico de la dogmática jurídica. Para ello se asume la pertinencia de la comprensión de los partícipes de dicha práctica como herramienta tanto para los efectos de realizar una descripción verosímil de su actividad, como de las pretensiones de validez implícitas en ellas. En este artículo la referencia se restringirá a la dogmática penal. Como toda comparación es dependiente tanto del parámetro elegido como del objeto sometido a evaluación, primero se realiza una breve revisión de la discusión que se ha desarrollado en torno a la racionalidad de la práctica científica, para luego realizar una delimitación del discurso que constituye a una teoría dogmática, la(s) pretensión(es) de validez que pueden ser reconocidas en él, proponiendo una demarcación de las condiciones mínimas que debe poseer una teoría dogmática para que sea calificable como tal. Evaluados los elementos relevantes para el análisis comparativo se vuelve sobre la pregunta inicial descartando las propuestas teóricas que condicionan la calificación de científica para el discurso dogmático a una modificación de su objeto y método, demostrando con ejemplos la idoneidad analógica del parámetro formulado por Lakatos para los programas de investigación científicos.

Palabras clave: ciencia jurídico penal, dogmática jurídica, valor científico del discurso dogmático, racionalidad de la dogmática jurídico penal.

\footnotetext{
* Agradezco los pertinentes comentarios formulados por Marcos Contreras a este artículo. Me encuentro especialmente en deuda con Antonio Bascuñán quien, junto con facilitarme fundamentales referencias bibliográficas para desarrollar este trabajo, fue quien me instruyó inicialmente en esta temática.
} 


\title{
Polít. crim. Vol. 14, № 27 (Julio 2019), Art. 16, pp. 549-598 \\ [http://politcrim.com/wp-content/uploads/2019/06/Vol14N27A16.pdf]
}

\begin{abstract}
The article develops an alternative proposal of analysis to the traditional question about the scientific value of legal theory. For it the pertinence of the participants' understanding of this practice is assumed as a tool both for the purposes of making a credible description of their activity, as well as the validity of the pretenses implicit in them. In this article the reference will be restricted to criminal theory. As any comparison is dependent so much in the parameter chosen as the object subject to evaluation, it is first performed a brief review of the discussion that has developed around the rationality of scientific practice, to then make a delimitation of the discourse that constitutes a legal theory, the pretension(s) of validity that can be recognized in it, proposing a demarcation of the minimum conditions that a legal theory must possess to be qualified as such. Evaluated the relevant elements for the comparative analysis we go back to the initial question discarding the theoretical proposals that condition the scientific qualification for the dogmatic discourse to a modification of its object and method, demonstrating with examples the analogue suitability of the parameter formulated by Lakatos for Scientific Research Programs.
\end{abstract}

Keywords: criminal legal science, legal theory, scientific value of dogmatic discourse, rationality of criminal legal theory.

\section{Zusammenfassung:}

Der Artikel entwickelt einen alternativen Ansatz zur traditionellen Analyse der Frage nach dem wissenschaftlichen Wert der Rechtsdogmatik. Dabei wird von der Angemessenheit des Verständnisses dieser Praxis durch seine Beteiligten als Mittel sowohl für den Zweck einer glaubwürdigen Beschreibung ihrer Tätigkeit, als auch der Ausführung der in ihr implizierten Geltungsansprüche ausgegangen. In diesem Artikel begrenzen sich die Hinweise auf die Strafrechtsdogmatik. Da jeder Vergleich sowohl von den gewählten Parametern wie vom auszuwertenden Objekt abhängig ist, wird zunächst eine bündige Überprüfung der bisherigen Diskussion hinsichtlich der Rationalität der wissenschaftlichen Praxis durchgeführt, um sodann $\mathrm{zu}$ einer Abgrenzung des Diskurses, was eine Rechtsdogmatik und dem darin enthaltenen Geltungsanspruch den eine Rechtsdogmatik umfassen muss, zu kommen. In diesem Kontext werden Mindestbedingungen vorgeschlagen, die jede dogmatische Lehre besitzen muss, um als solche klassifizierbar zu sein. Im Anschluss wird die Frage nach dem wissenschaftlichen Wert der Rechtsdogmatik wieder aufgegriffen und der Vorschlag, die Bewertung der Rechtsdogmatik als Wissenschaft von einer Modifizierung seines Gegenstandes und Methode abhängig zu machen, verworfen. Die Eignung des von Lakatos formulierten Parameters für wissenschaftliche Forschungsprogramme wird anhand von Beispielen dargestellt.

Stichworte: strafrechtliche Wissenschaft, juristische Dogmatik, wissenschaftlicher Wert des dogmatischen Diskurses, Rationalität der Strafrechtsdogmatik. 


\section{SCHURMANN, Miguel “¿Es científico el discurso elaborado por la dogmática jurídica? Una defensa de la pretensión de racionalidad del discurso dogmático elaborado por la ciencia del derecho penal".}

\section{Introducción}

En los países de tradición jurídica continental, caracterizados por la asunción de la Legislación como fuente principal del derecho, ${ }^{1}$ se ha creado un discurso profesional especialmente dedicado a racionalizar el derecho de la sociedad. Este discurso ha sido elaborado por abogados especialmente dedicados a la sistematización del derecho vigente, a los cuales se les ha denominado dogmática jurídica. ${ }^{2}$ La dogmática jurídica se caracteriza por desarrollar un discurso especial, las teorías dogmáticas. Este discurso se encuentra caracterizado tanto por su objeto, el derecho vigente, como por su método, el que es denominado como método jurídico. ${ }^{3} \mathrm{Su}$ objeto de referencia, por su parte, delimita tanto sus pretensiones, como su alcance real. Así, sus interpretaciones y creaciones sólo tienen valor en cuanto asumen la validez del derecho vigente.

Los elaboradores de dicho discurso (los partícipes de la práctica) suelen denominarla sin mayores complejos como "ciencia jurídica" o "ciencia del derecho", 4 especificando su ámbito de validez de acuerdo a la rama del derecho a la que adscriben. Así, por ejemplo, es posible reconocer una ciencia del derecho penal. Junto a la utilización de la denominación ciencia, es usual reconocer en los miembros de la comunidad dogmática una descripción de las actividades propias de la dogmática jurídica, que resulta idónea para delimitar cuál

\footnotetext{
${ }^{1}$ Para una descripción y explicación de esta tendencia histórica y su fundamento, ver en GARCÍA DE ENTERRÍA, Eduardo y MENÉNDEZ MENÉNDEZ, Aurelio, El Derecho, la Ley y el Juez dos estudios, Madrid: Civitas, 1990, pp. 23 y ss. Otra explicación se encuentra en ROSS, Alf. Sobre el Derecho y la justicia, Eudeba: Buenos Aires, Argentina, 1970. Capítulo segundo.

${ }^{2}$ Aquí es utilizada la expresión dogmática jurídica en el primer sentido descrito por Núñez. En sus propios términos, "equivale sin más a la actividad desarrollada por los estudiosos del derecho (y/o a sus resultados y método). Es decir, la expresión es usada, en este primer sentido, como sinónima de "ciencia del derecho"”. Así en NÚÑEZ VAQUERO, Álvaro. "Dogmática Jurídica", Eunomía. Revista en Cultura de la Legalidad, Número 6, marzo - agosto (2014), pp. $245 \quad-260, \quad$ p. $246 . \quad$ En: https://erevistas.uc3m.es/index.php/EUNOM/article/view/2213/1148 [visitada el 22.03.2018].

${ }^{3}$ La caracterización del método jurídico es tratado en detalle en libros especialmente dedicados a ello. El más reconocido en este ámbito es ENGISCH, Karl. Introducción al pensamiento jurídico. Editorial Comares, 2016. En este sentido, destacando la relevancia del método, también VERGARA BLANCO, Alejandro. "Teoría del Derecho, Filosofía del Derecho y Doctrina Jurídica", Revista de Derecho de la Pontificia Universidad Católica de Valparaíso, 2015, pp. 623 - 660, $\quad$ p. 631. En: http://www.scielo.cl/scielo.php?script=sci arttext\&pid=S0718-68512015000100019 [visitada el 22.03.2018]. http://www.scielo.cl/scielo.php?script=sci_arttext\&pid=S0718-68512015000100019.

${ }^{4}$ En ese sentido afirma Vega, que los dogmáticos carecen de una crisis de autoafirmación de su racionalidad, al contrario trabajan bajo la convicción de que constituyen una disciplina con una metodología asentada que posee plena racionalidad y operatividad para su ámbito. VEGA, Jesús. "las calificaciones del saber jurídico y la pretensión de racionalidad del derecho”, Doxa -Cuadernos de Filosofía del Derecho No 32, 2009, pp. 375 414, p. 377. Disponible en http://www.cervantesvirtual.com/obra/las-calificaciones-del-saber-juridico-y-lapretension-de-racionalidad-del-derecho/ [visitada el 22.03.2018]. Sin embargo, la sobreabundancia de contribuciones teóricas en las últimas décadas, un mal(?) del que aun no adolecemos como comunidad en Chile, ha planteado la pregunta tanto por el adecuado análisis de esas contribuciones dentro de la comunidad dogmática, así como por el adecuado camino por el progreso teórico en el ámbito jurídico-penal. Ver infra 2.2. y SCHÜNEMANN, Bernd, "Standpunkte der deutschen Strafrechtslehrer zu den Zukunftsperspektiven der Rechtswissenschaft und der akademischen juristischen Ausbildung in Deutschland", Zeitschrift für Internationale Strafrechtsdogmatik (ZIS). $N^{\text {o }}$ 6/2012, pp. 302- 312, p. 305. En: http://www.zisonline.com/dat/artikel/2012_6_682.pdf [visitada el 22.03.2018].
} 


\section{Polít. crim. Vol. 14, № 27 (Julio 2019), Art. 16, pp. 549-598 [http://politcrim.com/wp-content/uploads/2019/06/Vol14N27A16.pdf]}

discurso puede ser adscrito a dicha categoría y cuál, por defecto, debe ser excluido de la misma. Pese a la autoafirmación de su carácter de ciencia, por parte de los partícipes del discurso dogmático, en las últimas décadas se ha vuelto recurrente la pregunta sobre la corrección de la asociación de la práctica dogmática a la categoría de ciencia o su descripción mediante el uso del adjetivo científico. ¿Es la dogmática jurídica una ciencia? ${ }^{5}$ La respuesta a esta pregunta depende de una serie de presupuestos destinados a clarificar, por una parte, qué entendemos por ciencia y conocimiento científico y, por la otra, qué actividades y método definen o deben definir la práctica de la dogmática jurídica. Sin embargo, cabe reflexionar también acerca de la necesidad de dicha calificación como eventual requisito para el reconocimiento del carácter racional de la práctica y su valor para la sociedad. De este modo, a la pregunta anterior debe añadirse: ¿Por qué la dogmática jurídica debería aspirar a ser ciencia? Como ya lo han señalado diversos autores, la pregunta se ha planteado con un evidente sesgo teórico: el paradigma de racionalidad han sido las teorías científicas de carácter empírico. Este sesgo es producto de la influencia que ejerció el programa del Positivismo Lógico en las ciencias sociales a comienzos del siglo XX. ${ }^{6}$

La discusión desarrollada para responder a la pregunta por el valor científico del análisis del derecho puede ser planteada en otros términos. En vez de preguntar binariamente si el discurso dogmático es o no ciencia, como parámetro socialmente aceptado de racionalidad, es posible indagar en qué sentido la dogmática jurídica contribuye de un modo específico a la racionalidad de la argumentación jurídica y de la decisión jurisdiccional. ${ }^{7}$ El objeto de este trabajo consiste en evaluar el carácter racional del discurso elaborado por la dogmática jurídica y las condiciones de posibilitación y desarrollo de una ciencia del derecho penal. Para ello comenzaré por una descripción del objeto de análisis, las teorías desarrolladas para interpretar y aplicar el derecho vigente, delimitándola respecto de otras reflexiones realizadas sobre el derecho. Para los efectos de describir la auto comprensión de la dogmática jurídica y facilitar la conmensurabilidad de las diversas opiniones, se elije aquella elaborada para el derecho penal $(2) .{ }^{8}$ Una vez descrito y delimitado el objeto de

\footnotetext{
${ }^{5}$ Con esta pregunta comienza el artículo de BERNASCONI RAMÍREZ, Andrés. "El carácter científico de la dogmática jurídica", Revista de Derecho Universidad Austral de Chile. Volumen 20, № 1. Julio de 2007, pp. $9 \quad-\quad 37, \quad$ p. $\quad 10 . \quad$ En: $\quad$ https://scielo.conicyt.cl/scielo.php?script=sci_abstract\&pid=S071809502007000100001\&lng=es\&nrm=iso [visitada el 22.03.2018].

${ }^{6}$ Así en VEGA "Las calificaciones del saber jurídico", cit. nota n 4, pp. 386 y ss.

${ }^{7}$ En este sentido BASCUÑÁN RODRÍGUEZ, Antonio. "Observaciones sobre la ciencia del derecho", Revista Derecho y Humanidades. Santiago, Chile. Número 6 (1998), pp. 15-25. p. 15. Disponible en: https://revistas.uchile.cl/index.php/RDH/article/view/25785/27113 [visitado el 22.03.2018].

${ }^{8}$ Si bien la elección responde en parte a la cercanía del autor con el área dogmática, reconociendo por cierto que este análisis puede realizarse con cualquier área del Derecho, la elección se debe principalmente a que dentro de las diversas teorías dogmáticas producidas en la actualidad, las teorías dogmáticas elaboradas para analizar y describir el derecho penal se destacan por su vinculación a paradigmas de mayor complejidad y abstracción, pretendiendo fundar las soluciones interpretativas propuestas con presupuestos metodológicos debidamente fundados (Ver 2.2). La capacidad de estas teorías para vincularse con los discursos elaborados por el derecho europeo continental, especialmente con el desarrollado en España y Alemania, le otorgan una repercusión y refutabilidad mayor al promedio. A una conclusión análoga arriba Bernasconi en BERNASCONI RAMÍREZ, "El carácter científico" cit. nota $\mathrm{n}^{\circ}$ 5, p. 28 y especialmente en la nota 51 . Una postura crítica de la prevalente influencia de la dogmática alemana en nuestro medio se encuentra en MATUS ACUÑA, Jean Pierre. "Por qué citamos a los alemanes y otros apuntes metodológicos". En: EL MISMO,
} 


\section{SCHURMANN, Miguel “¿Es científico el discurso elaborado por la dogmática jurídica? Una defensa de la pretensión de racionalidad del discurso dogmático elaborado por la ciencia del derecho penal".}

análisis, se revisará críticamente el parámetro de racionalidad con el cual suelen ser evaluadas las teorías dogmáticas, la discusión desarrollada en el ámbito de la filosofía de las ciencias y cómo él ha evolucionado hacia un paradigma de racionalidad crítica (3). Una vez que se haya analizado el parámetro evaluativo con el que habitualmente se compara la práctica dogmática, se evalúan las pretensiones de validez del discurso dogmático, de modo de determinar con precisión en qué sentido y qué tipo de afirmaciones pretenden ser reconocidas como racionales y demarcar qué puede contar como una teoría dogmática (4). Posteriormente, (5) se vuelve sobre la pregunta original, evaluando críticamente las respuestas que se han entregado en nuestro medio, concluyendo con la propuesta de un modelo racionalista de evaluación del progreso dogmático mediante la adaptación de los programas de investigación científicos propuestos por Lakatos adaptados a la dogmática, el cual es probado mediante una revisión, adoptando la perspectiva del partícipe de la práctica, de la sucesión de paradigmas interpretativos para la dogmática penal. Finalizando con una breve conclusión.

\section{Delimitación y descripción de las teorías dogmáticas. El caso de la ciencia del derecho penal}

\subsection{Las teorías dogmáticas frente a otros discursos elaborados sobre el Derecho}

En forma preliminar, se debe diferenciar dos tipos de discurso que se refieren de forma distinta al derecho como objeto de análisis. Así, se debe distinguir entre las teorías que se refieren, por una parte, a la estructura del derecho y de las normas con independencia de un contexto espacio-temporal específico, las cuales se insertan dentro de lo que se denomina como teoría general del derecho; y por la otra, a las teorías elaboradas a partir del derecho vigente de un lugar y tiempo determinado, es decir contextualizadas, esto es lo que se denominan teorías dogmáticas. ${ }^{9}$ La teoría general del derecho tiene como finalidad dar una explicación verosímil de la estructura del Derecho y de las normas sin tener como referencia un sistema jurídico determinado. Ejemplos paradigmáticos de estas teorías son las desarrolladas por Hans Kelsen ${ }^{10}$ y H.L.A. Hart, ${ }^{11}$ entre otros. Por otra parte, las teorías dogmáticas se diferencian de aquellas por su especial objeto de referencia: un sistema

\footnotetext{
Derecho penal, criminología y política criminal en el cambio de siglo, Editorial Jurídica de Chile, 2011, pp. $311-347$, pp. 311 y ss.

${ }^{9}$ En un sentido similar, aunque distinguiendo entre distintos sentidos de "ciencia jurídica" ver NÚÑ̃E VAQUERO, Álvaro. "Ciencia Jurídica". En: Enciclopedia de Filosofía y Teoría del Derecho, 2015, vol. 1, pp. 601 - 631, p. 604. En https://archivos.juridicas.unam.mx/www/bjv/libros/8/3875/19.pdf [visitada 22.03.2018] Distinguiendo entre Ciencia Jurídica y Filosofía del Derecho ver CELIS DANZINGER, Gabriel. "Relaciones entre Filosofía del Derecho, Ciencia Jurídica y Teoría del Derecho", Revista de Derecho Escuela de Postgrado. $\mathrm{N}^{\circ}$ 1, dic. 2011. pp. 121 y ss. y VERGARA BLANCO, "Teoría del Derecho, Filosofía del Derecho y Doctrina Jurídica", cit. nota ${ }^{\circ} 3$, pp. 644 y ss. Dado que uno de los objetos de este trabajo es evaluar el carácter científico de las teorías dogmáticas, se ha preferido evitar una relación de sinonimia entre dogmática y ciencia jurídica, de modo que la denominación no prejuzgue las conclusiones o lleve a equívocos en la línea argumental.

${ }^{10}$ KELSEN, Hans. Teoría Pura del Derecho. México: D.F. Editorial Porrúa, 1998.

${ }^{11}$ HART, H.L.A. El Concepto de Derecho, Buenos Aires: Abeledo-Perrot. 1977.
} 


\section{Polít. crim. Vol. 14, № 27 (Julio 2019), Art. 16, pp. 549-598 [http://politcrim.com/wp-content/uploads/2019/06/Vol14N27A16.pdf]}

jurídico determinado y vigente en un espacio y tiempo específico. ${ }^{12}$ La caracterización de las teorías dogmáticas a través de su objeto, el derecho vigente, no prejuzga en caso alguno la pertinencia de los argumentos a partir (o a través) de los cuales se interpreta el derecho vigente, esto es, de cómo se estructuran las teorías dogmáticas, las cuales por cierto pueden considerar una mayor o menor apertura a consideraciones lógicas o filosóficas.

Una primera aproximación a la noción de dogmática jurídica, para el efecto de delimitar el objeto de nuestro análisis, es entenderla como un tipo de discurso elaborado por la cultura jurídica europeo-continental, ${ }^{13}$ que se caracteriza por asumir la responsabilidad de realizar una reconstrucción racional del sistema jurídico, mediante una forma especial de razonamiento, el razonamiento jurídico. En la actualidad, las teorías dogmáticas constituyen componentes cruciales de la comprensión del ordenamiento jurídico, dado que permiten entender de manera comprehensiva o sistemática todo o parte del ordenamiento, entregando a la comunidad jurídica decisiones interpretativas sobre la aplicabilidad del derecho vigente a grupos de casos o supuestos de hecho. ${ }^{14} \mathrm{Su}$ pretensión de imparcialidad y la falta de constreñimientos cognitivos y temporales lo diferencia de los operadores de la práctica jurídica, tanto abogados como jueces. ${ }^{15}$

De acuerdo con Núñez, una definición comprensiva de dogmática jurídica supone describirla como "la actividad realizada por los estudiosos del derecho que tiene como objetivo establecer la calificación deóntica que, en un determinado sistema jurídico, se atribuye a tipos de acciones (casos genéricos) -pero en algunas ocasiones también a conductas concretas (casos individuales) - y al que el sistema jurídico de referencia no reconoce algún valor en ningún procedimiento jurídico. Es decir, la actividad -pero también su método y resultado- que pretende precisar la consecuencia jurídica que un ordenamiento jurídico vigente asocia a un determinado tipo de comportamiento". ${ }^{16}$ En el

\footnotetext{
${ }^{12}$ Esta distinción se ajusta a la recogida por Canaris, quien diferencia a las teorías jurídicas dogmáticas, de las teoréticas. Así en CANARIS, Claus-Wilhelm. Función, estructura y falsación de las teorías jurídicas. Editorial Civitas S.A. Madrid, España. 1995. pp. 30 y ss., especialmente nota 11.

${ }^{13}$ Esta delimitación tiene la virtud de excluir de la descripción del objeto de análisis a los discursos elaborados en el ámbito del derecho anglosajón, los cuales, al regirse por objetivos prioritariamente predictivos, cambian (o amplían) el objeto de análisis desde las normas hacia los factores que inciden realmente en la dictación de una sentencia, los que en caso alguno se reducirían al reconocimiento de una regla como razón para la acción. Una descripción de dicha actividad en el ámbito penal se encuentra en MATUS ACUÑA "Por qué citamos a los alemanes...", cit. nota nº 8, pp. 335 y ss.

${ }^{14}$ Una descripción de la labor desarrollada por la dogmática para la sociedad es la desarrollada por Luhmann, quien, asumiendo la perspectiva del observador, la describe como una función relacional en una sociedad altamente diferenciada que consiste en "1) la integración, interna del sistema, de input y output, que no permite ni una maximización del input (por ejemplo, una búsqueda ilimitada de información o una mayor profundidad en el análisis del caso) ni una optimización del output en el sentido de un social engineering de programación final, propio del Estado del bienestar, 2) la adaptación de esta prestación a estructuras y problemas del entorno social del sistema jurídico, y 3) el grado de generalización y especificación de aquel plano de sentido en el que ambas prestaciones puedan conectarse. La dogmática jurídica sólo surge como configuración propia, que puede distinguirse de las normas jurídicas, cuando el sistema jurídico esta suficientemente diferenciado dentro del sistema social" LUHMANN, Niklas. Sistema Jurídico y Dogmática Jurídica. Centro de Estudios Constitucionales. Madrid, España, 1983, p. 112.

${ }^{15}$ NÚÑEZ VAQUERO, "Ciencia Jurídica", cit. nota n ${ }^{\circ}$ 9, p. 608.

${ }^{16}$ NÚÑEZ VAQUERO, "Dogmática jurídica", cit. nota ${ }^{\circ}$ 2, p. 247. Una descripción de los diversos significados de la expresión se encuentra en la p. 246 del mismo artículo.
} 


\section{SCHURMANN, Miguel “¿Es científico el discurso elaborado por la dogmática jurídica? Una defensa de la pretensión de racionalidad del discurso dogmático elaborado por la ciencia del derecho penal".}

establecimiento de la calificación deóntica se realizan no solo enunciados descriptivos -una reproducción y sistematización de lo que establece el derecho vigente-, sino que también prescriptivos, en tanto la propuesta interpretativa se funda en razones que justifican cómo debe ser entendido el derecho vigente, adaptando sus soluciones a exigencias materiales de justicia, a requerimientos ontológicos o bien para solucionar defectos lógicos. ${ }^{17}$

\subsection{La autocomprensión de la dogmática penal}

Durante las últimas décadas diversos factores han llevado a que los teóricos o dogmáticos del derecho penal alemán reflexionen tanto sobre el carácter científico de su práctica -y cuáles serían los criterios para delimitarla respecto de otros discursos referidos al derecho vigente en materia penal-, como sobre cuáles son los principios y objetivos que gobiernan o deben gobernar la práctica de la ciencia del derecho penal y su transmisión en las universidades. Dicha reflexión se ha dado en el contexto de un creciente número de publicaciones, las cuales dan cuenta de una disputa de grandes modelos teóricos o paradigmas rivales, bajo los cuales diversos autores discuten tanto sobre los fundamentos del sistema de imputación, como respecto a la solución de problemas interpretativos concretos del derecho penal vigente en Alemania. La discusión llevada a cabo en Alemania ha sido atentamente seguida en nuestra cultura jurídica, tal como da cuenta la investigación desarrollada por Matus. ${ }^{18}$

La dogmática penal se reconoce como un actividad que se encuentra delimitada por su vinculación a dos sistemas de poder estatal, la configuración de las leyes como expresión de la política criminal por parte del Legislador, que determina el objeto y, por ende, el input de la dogmática y, por el otro lado, la jurisprudencia de los tribunales, la cual a través de una relación simbiótica, en parte es el resultado del desarrollo de la dogmática y su método, en este sentido su output, al inclinarse en sus decisiones a favor de una determinada postura sostenida en la doctrina. ${ }^{19}$ La principal función que se le atribuye a la dogmática es el control crítico de la racionalidad de las decisiones adoptadas en el ejercicio del poder punitivo estatal. La relevancia y utilidad de la dogmática como práctica cultural es dependiente de su capacidad o potencia aclaratoria, la que es dependiente -a su vez- de la capacidad de excluir de ella afirmaciones teóricas que puedan ser calificadas como espontáneas, singulares, ilógicas o arbitrarias. ${ }^{20} \mathrm{La}$ posibilidad de excluir pretendidas teorías dogmáticas o enunciados sobre el derecho vigente respecto de lo que se debe

\footnotetext{
${ }^{17}$ Dicha descripción de la actividad dogmática no prejuzga la evaluación científica ni desempeño racional de sus enunciados. Particularmente problemáticos son a este respecto los enunciados prescriptivos, como se verá en infra 4.2.

${ }^{18}$ MATUS ACUÑA "Por qué citamos a los alemanes", cit. nota nº 8, pp. 311 y ss.

${ }^{19}$ En este sentido, la determinación de la postura teórica dominante en una comunidad jurídica suele determinarse tanto en relación al número y valor de las propuestas teóricas que apoyan una determinada solución, como en el grado de acogida que dicha solución tiene en los tribunales. Sin embargo, sería incorrecto atribuir a la jurisprudencia el poder de adjudicar al triunfador de una disputa dogmática o de falsear a la teoría dogmática no favorecida (ver infra nota 159).

${ }^{20}$ En este sentido KINDHÄUSER, Urs. "Die deutsche Strafrechtsdogmatik zwischen Anpassung und Selbstbehauptung - Grenzkontrolle der Kriminalpolitik durch die Dogmatik“, Zeitschrift für gesamte Strafrechtswissenschaft (ZStW), 2009, Heft 4, pp. 954 - 964, p. 954.
} 


\section{Polít. crim. Vol. 14, № 27 (Julio 2019), Art. 16, pp. 549-598 [http://politcrim.com/wp-content/uploads/2019/06/Vol14N27A16.pdf]}

entender como parte integrante de la dogmática jurídica, vendría dado por la falta de satisfacción por parte de ellas de un parámetro normativo sobre lo que entendemos como condiciones mínimas de posibilitación de una práctica dogmática penal con carácter científico. Dado que, si bien la dogmática jurídica constituye una práctica deficitaria de reconocimiento institucional, frente a las prácticas estatales de creación y aplicación del derecho, dicho déficit sólo puede ser compensado mediante un superávit de racionalidad, que sirva como criterio de reconocimiento de la solución propuesta por una teoría dogmática como correcta para un determinado caso complejo. Es precisamente dicho criterio de reconocimiento, cuya existencia es reconocida por los partícipes de la dogmática, es aquél que debe ser dilucidado a través de una comprensión de la práctica.

El carácter crítico de la dogmática se manifiesta tanto respecto a su input como a su output. De esta forma, se plantean habitualmente como deberes de la dogmática tanto la crítica de la actividad del legislador, en tanto -por ejemplo- criminalice inadecuadamente conductas desatendiendo las (eventuales) restricciones constitucionales al respecto, la reconstrucción del sistema jurídico bajo determinados ideales de racionalidad, y la crítica de las decisiones emanadas de los tribunales, ${ }^{21}$ no limitando su actividad a la mera anticipación de las decisiones por parte de ellos, sino que controlando la corrección de sus decisiones con el sistema de derecho vigente, en los términos reconstruidos por la dogmática. ${ }^{22}$

Si bien las condiciones de cientificidad y su formulación pueden variar de un autor a otro, existe un consenso tanto en relación a la existencia de un parámetro, como uno relativo a sus contornos. ${ }^{23}$ De acuerdo a Kindhäuser, por ejemplo, son tareas de la dogmática y, por ende, condiciones de su cientificidad, las siguientes: (i) una adecuada vinculación con lo empírico, en tanto el Derecho constituye un orden de deber que transforma hechos naturales en hechos institucionales; ${ }^{24}$ (ii) un análisis y reconstrucción de las condiciones semánticas, pragmáticas y deónticas bajo las cuales los enunciados dogmáticos pueden ser formulados y aplicados libres de contradicción; ${ }^{25}$ (iii) una adecuada sistematización mediante la construcción de teorías dogmáticas vinculando soluciones interpretativas del derecho vigente -formuladas mediante los tradicionales criterios interpretativos- a los paradigmas

\footnotetext{
${ }^{21}$ SCHÜNEMANN, "Standpunkte der deutschen Strafrechtslehrer", cit. nota n ${ }^{\circ}$ 4, p. 304.

${ }^{22}$ Luhmann advierte que en la actualidad, la dogmática ha realizado un paulatino cambio en su punto de gravedad, desde la frontera del input a la del output, como un reflejo de la sociedad moderna. La dogmática se ha caracterizado por orientar su discurso al aseguramiento de la justicia del caso concreto. Sin embargo, esto genera un problema para la auto-confirmación de la sociedad, dado que la previsión de consecuencias y el control planificado de situaciones complejas es un requisito para realizar acciones orientadas al éxito. La función del derecho es asegurar expectativas. LUHMANN, Sistema jurídico, cit. nota nº 14, pp. 54 y ss. y 61 y ss.

${ }^{23}$ Una concepción más restringida de la cientificidad de la actividad dogmática postula Jakobs, quien afirma que "...la ciencia del Derecho penal debe dar respuesta a la pregunta acerca de cuál Derecho penal es legítimo en una época determinada y cuál no lo es [...] Corresponde a la ciencia elaborar la autocomprensión normativa de su tiempo, reconducir el conjunto de instituciones jurídicas al fundamento que les da legitimidad." JAKOBS, Günther. El derecho penal como disciplina científica, Navarra: Thomson Civitas, 2008, pp. 22 y ss. ${ }^{24}$ Un ejemplo de la necesidad de esta vinculación se presenta en la capacidad de incluir en la categoría de la culpabilidad, bajo una perspectiva jurídico-penal, los avances en el ámbito de la neurociencia.

${ }^{25}$ Por esta vía se explicita la verdad analítica y lógica inmanente a la estructura de la teoría de la imputación, la cual es independiente de la específica configuración de lex lata en un determinado ordenamiento jurídico, permitiendo una discusión universal.
} 


\section{SCHURMANN, Miguel “¿Es científico el discurso elaborado por la dogmática jurídica? Una defensa de la pretensión de racionalidad del discurso dogmático elaborado por la ciencia del derecho penal".}

valorativos específicos del ámbito penal. ${ }^{26}$ Finalmente, constituye un deber de la dogmática penal (iv) la indagación de los fundamentos materiales del derecho penal y la construcción de paradigmas dentro de los cuales se mueven las teorías dogmáticas. Así, el enfrentamiento de las posturas teóricas rivales se presenta tanto en el nivel de los fundamentos y paradigmas, como en el nivel de la sistematización y propuestas interpretativas concretas del derecho vigente alemán. Sin embargo, no es posible establecer un criterio verificacionista para determinar cuál es la teoría correcta, sino que solo sostener dentro de la discusión dogmática con pretensiones de corrección aquella que no haya sido falseada $^{27} .^{28}$

Reconociendo el carácter controvertido del apelativo de ciencia para la actividad realizada por la dogmática jurídica, Schünemann rechaza la pertinencia de un concepto empírico de ciencia y sostiene que la institucionalización de la ciencia jurídico-dogmática -como una prestación cuya cientificidad no puede ser negada- depende de la satisfacción de tres garantías de corrección, a saber, (i) que el carácter prohibido o mandatado de una conducta no puede ser producto de arbitrariedad, sino que de fundamentos racionales; ${ }^{29}$ (ii) que el sistema de conceptos y de argumentos creado al efecto se encuentre libre de contradicciones; y (iii) que los estándares observados en la práctica sean expuestos a crítica continuamente. Así, la racionalidad, intersubjetividad y controlabilidad de los enunciados dogmáticos serían elevados a un carácter decisorio en la evaluación de su cientificidad, bajo un paradigma interpretativo de evaluación. ${ }^{30}$

El resultado de lo anterior ${ }^{31}$ ha sido el desarrollo de una dogmática penal gobernada por complejos sistemas o constructos teóricos (también denominados paradigmas) que vinculan

\footnotetext{
${ }^{26}$ La falta de vinculación sistemática de una solución interpretativa a un paradigma es precisamente lo que caracteriza a la tópica en oposición a la ciencia, como caracterización de la dogmática penal. En este sentido, los criterios reconocidos para refutar teorías dogmáticas presuponen la conexión sistemática de la propuesta interpretativa tanto con el programa investigativo como con el tenor literal de la disposición interpretada. Así constituyen criterios generalmente reconocidos de falsación de teorías dogmáticas: (i) la existencia de una contradicción valorativa en la teoría; (ii) la falta de correspondencia de la teoría con el tenor literal de la ley; (iii) el ignorar las relaciones sistemáticas del ordenamiento jurídico; y (iv) la configuración de una interpretación teórica que contradiga el fin de la norma. Ver infra 5.3 y KINDHÄUSER, "Die deutsche Strafrechtsdogmatik", cit. nota ${ }^{\circ} 20$, pp. 958 y ss.

${ }^{27}$ La correspondencia de este criterio negativo de racionalidad propuesto por Kindhäuser y la evolución de la discusión en filosofía de las ciencias es evidente, como se verá en infra 3.1.

${ }^{28}$ KINDHÄUSER, "Die deutsche Strafrechtsdogmatik", cit. nota n ${ }^{\circ} 20$, pp. 955 y ss.

${ }^{29}$ Aquí se confunde la pretensión de racionalidad del Derecho con la pretensión de racionalidad de la dogmática jurídica. Sin embargo, dicha distinción es imprescindible para delimitar qué constituye una teoría dogmática y cómo ella desempeña su pretensión de racionalidad. Ver infra 4.2-3.

${ }^{30}$ SCHÜNEMANN, "Standpunkte der deutschen Strafrechtslehrer", cit. nota n ${ }^{\circ}$, p. 303.

${ }^{31}$ La descripción de causa y efecto aquí responde a una descripción analítica, no necesariamente histórica. Una exposición de la evolución histórica de la ciencia del derecho penal alemana se encuentra en JAKOBS, El derecho penal como disciplina científica, cit. nota $\mathrm{n}^{\circ} 23$, pp. 37 y ss. Para un análisis de la sucesión de los paradigmas interpretativos históricamente dominantes en los últimos 150 años y un análisis de su sucesión en el tiempo de acuerdo a parámetros de racionalidad, ver SCHÜNEMANN, Bernd. "Introducción al pensamiento sistemático en Derecho Penal”. En: SILVA SÁNCHEZ, Jesús-María (Trad.), El sistema moderno del derecho penal cuestiones fundamentales, Editorial Tecnos: Madrid, 1991, pp. 31 - 77, pp. 43 y ss.
} 


\section{Polít. crim. Vol. 14, No 27 (Julio 2019), Art. 16, pp. 549-598 [http://politcrim.com/wp-content/uploads/2019/06/Vol14N27A16.pdf]}

decisiones metodológicas con fundamentos materiales y que intentan fundar la interpretación del derecho vigente como una aplicación necesaria y coherente de sus premisas. En otras palabras, el carácter científico de dichas construcciones radicaría principalmente en la vinculación -libre de contradicción- de las propuestas interpretativas del derecho vigente a presupuestos metodológicos y fundamentos que pretenden ser reconocidos como racionales. El principal producto formulado en dicho sentido es la teoría general del delito o del hecho punible, el cual vincula las diferentes disposiciones de la denominada parte general del derecho penal bajo la idea de un sistema que prevé tanto los presupuestos generales de atribución de responsabilidad penal, como los momentos analíticos en que los presupuestos previstos en el tipo de la parte especial son considerados en el sistema. De este modo, dichos fundamentos poseerían el grado de abstracción necesario para ser adaptados en otros sistemas jurídicos, en donde la comunidad dogmática trabaja asumiendo la vigencia y aplicabilidad de dichos modelos. ${ }^{32}$ Junto a este ideal de coherencia interna de las teorías dogmáticas se encuentra la pretensión de que ellas den cuenta de forma verosímil del derecho vigente en el que pretendan aplicación. Así las teorías dogmáticas responden simultáneamente al deber de coherencia interna y de verosimilitud con el ordenamiento jurídico. Esta pretensión de verosimilitud puede llevar a las teorías dogmáticas a adecuar sus fundamentos, ya sea modificándolos, de modo de integrar una determinada consecuencia jurídica dentro de su matriz teórica, o aislando una determinada aplicación teórica dentro de su paradigma, señalizándola como anómala. ${ }^{33}$

Si bien los paradigmas que más reconocimiento han recibido en las últimas décadas son aquellos denominados funcionalistas, y que han sido desarrollados principalmente por los profesores Claus Roxin y Günther Jakobs, ${ }^{34}$ esto no quiere decir que cada autor o grupo de autores deba realizar por sí mismo y autónomamente este camino desde los fundamentos de la teoría hasta sus aplicaciones pretendidas, al contrario, los nuevos aportes de la comunidad académica son elaborados e insertados en el conocimiento teórico existente en su tiempo, fundando y vinculando sus aportes a los paradigmas existentes. ${ }^{35} \mathrm{El}$ desarrollo de la dogmática, como todo desarrollo de conocimiento, tiene una naturaleza colectiva y

\footnotetext{
${ }^{32}$ Esta pretensión es explicitada y posteriormente criticada por Matus en MATUS ACUÑA "Por qué citamos a los alemanes", cit. nota $\mathrm{n}^{\circ} 8$, pp. 323 y ss. Una correcta respuesta se encuentra en VAN WEEZEL, Alex. “¿Por qué no citamos más (por ejemplo, a los alemanes)? Réplica a J. P. Matus”, Política Criminal, Número 6, 2008, D2-6, pp. 1 - 5, pp. 2 y ss. En: http://www.politicacriminal.cl/n_06/d_2 6.pdf [visitado el 22.03.2018]. Para un análisis detallado de este punto ver 4.3

${ }^{33} \mathrm{La}$ evaluación de una aplicación teórica como ajena a los fundamentos del paradigma teórico (ad-hoc) o como contradictoria con los fundamentos de una teoría (anomalía) suele ser identificado y criticado por los teóricos que sostienen un paradigma rival, lo que puede ser calificado como una falsación de una teoría dogmática. Tal como se describió previamente y se acreditará mediante ejemplos teóricos en infra 5.3, la acumulación de anomalías y la emergencia de un programa de investigación alternativo con mayor poder explicativo y heurístico para la solución de problemas interpretativos futuros justificarán el reemplazo del programa definitivamente falseado.

${ }^{34}$ Una descripción y valoración crítica se encuentra en ROXIN, Claus. "El nuevo desarrollo de la dogmática jurídico-penal en Alemania”, InDret 4/2012, pp. $1 \quad$ - $\quad 24, \quad$ En: http://www.raco.cat/index.php/InDret/article/view/260968/348124 [visitado el 22.03.2018].

35 JAKOBS, El derecho penal como disciplina científica, cit. nota $\mathrm{n}^{\circ}$ 23, p. 22; SCHÜNEMANN, "Introducción al pensamiento sistemático en Derecho Penal", cit. nota n 31, p. 80. Ver también infra 4.3.
} 


\section{SCHURMANN, Miguel “¿Es científico el discurso elaborado por la dogmática jurídica? Una defensa de la pretensión de racionalidad del discurso dogmático elaborado por la ciencia del derecho penal".}

(parcialmente) acumulativa. ${ }^{36} \mathrm{Al}$ mismo tiempo, si bien la exposición de grandes construcciones teóricas son las que más atención pueden haber atraído, no debe olvidarse que todas ellas son desarrolladas también a partir del reconocimiento de un problema práctico y su solución, ${ }^{37}$ existiendo un camino bidireccional entre los fundamentos teóricos y sus aplicaciones prácticas. Dichas contribuciones teóricas, calificadas como integrantes de la ciencia jurídico-penal, son deslindadas de aquellas que, deficitariamente en relación a los parámetros señalados, se limitan -por ejemplo- a elucidar el sentido de las expresiones utilizadas por el legislador sin vincularlo con los fundamentos y principios del Derecho Penal o a describir acríticamente lo afirmado por los tribunales de justicia en sus sentencias, los cuales no pueden ser calificados como teorías dogmáticas ni como enunciados elaborados como aplicaciones pretendidas a partir de ellas.

\section{La utilidad de la noción de racionalidad científica como paradigma evaluativo de la dogmática jurídica}

Tal como se señaló al comienzo, el carácter científico de la dogmática jurídica es dependiente de la noción de ciencia y conocimiento científico que sea propuesto, dado que dicha noción provee el parámetro según el cual pretende ser evaluada la dogmática. Para indagar en la constitución de dicho parámetro, en primer lugar, se revisará a grandes rasgos y sin pretensiones de exhaustividad la evolución de la discusión planteada en el seno de la filosofía de las ciencias sobre la labor y metodología de las teorías y de la práctica científica de la mano del debate planteado en el siglo XX por Popper, Kuhn y Lakatos ${ }^{38}$ a partir del paradigma de ciencia empírica postulado por el Positivismo Lógico, ${ }^{39}$ para luego realizar una valoración crítica de su utilidad como parámetro de evaluación de las teorías

\footnotetext{
${ }^{36}$ Ello no necesariamente implica que sea posible de calificar sin más como progresiva, como se verá especialmente en infra 3.1.2

${ }^{37}$ Quien llama la atención sobre este error en la apreciación general que se realiza de la dogmática alemana es Luis Greco. GRECO, Luis. “Dos formas de hacer dogmática jurídico-penal”, Revista Discusiones No 8. pp. 177-181. Disponible en http://www.cervantesvirtual.com/obra/dos-formas-de-hacer-dogmtica-jurdicopenal-0/ [visitado el 22.03.2018].

${ }^{38}$ Se ha excluido conscientemente de este análisis la propuesta teórica de Paul Feyerabend, dado que ella renuncia a otorgar un parámetro normativo de racionalidad científica. Su propuesta se encuentra en su conocido tratado: FEYERABEND, Paul. Tratado contra el método: esquema de una teoría anarquista del conocimiento. $4^{\circ}$ Edición, Madrid: Tecnos, 2000.

${ }^{39}$ El debate desarrollado por la filosofía de las ciencias tiene un objeto específico, las teorías científicas. Las teorías que se describirán en este apartado, constituyen teorías que se refieren a las teorías científicas, por ello, en ese sentido constituyen metateorías. Sin embargo, el modo de referencia difiere en cada uno de ellas. Así, si bien algunas teorías se refieren al método de asegurar la verdad (o más bien para testear la eventual falsedad) de las teorías científicas (principalmente Popper), otras lo hacen en relación a una comprensión histórica de la práctica científica, desde la perspectiva de su comunidad (Kuhn). Si bien la referencia a la metodología de la ciencia puede fácilmente remontarse hasta Aristóteles o incluso más, en este trabajo sólo se analizará simplificadamente la discusión sostenida entre los autores señalados, en tanto ella se corresponde plenamente a la pre-comprensión más extendida de lo que se entiende por ciencia y práctica científica y, por ello, suele incidir decisivamente en la noción de ciencia que es manejada por la filosofía del derecho y la dogmática jurídica. Por cierto, la discusión en la filosofía de las ciencias está lejos de agotarse a dichos autores. Una revisión analítica de la tradición teórica se encuentra en VON WRIGHT, Georg Henrik. Explanation and Understanding. Cornell University Press. 1971. Capítulo I, p. 1 - 33 (existe versión española "Explicación y Comprensión", Alianza Editorial, 1979).
} 


\section{Polít. crim. Vol. 14, No 27 (Julio 2019), Art. 16, pp. 549-598 [http://politcrim.com/wp-content/uploads/2019/06/Vol14N27A16.pdf]}

dogmáticas en el ámbito jurídico. ${ }^{40}$

\subsection{La evolución de la discusión planteada en el seno de la Filosofía de las Ciencias}

Para el Positivismo Lógico, las teorías científicas son enunciados empíricos que guardan una relación lógica. Estas teorías tienen proposiciones descriptivas universales con pretensión de verdad. La verdad de los enunciados sólo se verificará mediante su contrastación con el mundo empírico. ${ }^{41}$ Así, un experimento puede verificar el contenido de la verdad de un enunciado teórico, de modo que el conocimiento puede ser justificado racionalmente. Sin embargo, esta teoría -en los términos formulados- debía enfrentar el así denominado problema de la inducción. Este problema consiste en aceptar que la experiencia siempre será singular, mientras que la pretensión de la ciencia como conocimiento es la afirmación de universalidades. Así, si la verificación de un postulado universal siempre se realizará mediante experimentos singulares ¿cómo se puede entonces justificar racionalmente la verdad de un enunciado teórico de carácter universal, si la experiencia sólo puede demostrar postulados singulares? La respuesta que plantea el Positivismo Lógico es deductiva y no susceptible a su vez de verificación empírica: no existe una plena certeza de la verdad, sino que sólo una probabilidad de ella.

\subsubsection{El falsacionismo de Karl Popper}

Karl Popper, en "Conjeturas y Refutaciones", ${ }^{42}$ formula su teoría en oposición al empirismo, ya que para él, la observación no puede ser la fuente última del conocimiento. Por una parte, la percepción es falible, ya que "todo testigo debe siempre hacer uso frecuente, en su informe, de su conocimiento de personas, lugares, cosas, hábitos lingüísticos, convenciones sociales, etc." ${ }^{43}$ Por la otra "el error fundamental de la teoría filosófica de las fuentes últimas de nuestro conocimiento es que no distingue con suficiente claridad entre cuestiones de origen y cuestiones de validez" ${ }^{44}$ La validez del conocimiento no se debe necesariamente a su origen, ni a la confianza que se tenga de una fuente determinada, de modo que no conduzca al planteamiento de una teoría errónea. Tales fuentes indubitables del conocimiento no existen, por lo que propone cambiar la pregunta metodológica desde las fuentes del conocimiento a su validez. Con ello la pregunta fundamental a ser formulada es: ¿cómo podemos detectar y eliminar el error? Para Popper el error sólo puede ser detectado "criticando las teorías y presunciones de otros y criticando nuestras propias teorías y presunciones... [a esta postura] propongo llamar racionalismo

\footnotetext{
${ }^{40}$ La utilidad de este análisis vinculado a autores específicos no solo se restringe a la valoración global del conocimiento científico en el ámbito empírico como parámetro válido de evaluación para teorías dogmáticasjurídicas, sino que también, como se revisará posteriormente, porque para la evaluación del carácter científico de la dogmática es usual que los autores adopten alguna de estas concepciones particulares -popperiana, kuhniana o lakatiana- de la práctica dogmática para fundar sus posturas.

${ }^{41}$ Un sucinto análisis de la evolución de histórica de la teoría de la ciencia y su relación con la dogmática jurídica se encuentra en VEGA "Las calificaciones del saber jurídico", cit. nota n 4, pp. 381 y ss. La referencia al Positivismo Lógico se encuentra en las páginas 385 y ss.

${ }^{42}$ POPPER, Karl. Conjeturas y Refutaciones, Paidos: Barcelona, 1972.

${ }^{43}$ POPPER, Conjeturas y Refutaciones, cit. nota $n^{\circ} 42$, p. 46.

${ }^{44}$ POPPER, Conjeturas y Refutaciones, cit. nota $n^{\circ} 42$, p. 48.
} 


\section{SCHURMANN, Miguel “¿Es científico el discurso elaborado por la dogmática jurídica? Una defensa de la pretensión de racionalidad del discurso dogmático elaborado por la ciencia del derecho penal".}

crítico". ${ }^{45}$ Este principio obliga a considerar que ni la razón ni la observación son autoridades, ambas nos pueden conducir a error, la función científica más importante es contribuir al examen crítico de las conjeturas planteadas para explicar lo desconocido. Esta teoría también es denominada falsacionismo. Así, dado que la función científica es testear las conjeturas, de modo de buscar el error, el status científico de una teoría depende de su refutabilidad. Es decir, una teoría es científica ${ }^{46}$ si tiene base empírica y permite el examen crítico de sus proposiciones.

Por otra parte, en cuanto al tradicional problema de la inducción, Popper asume su falta de validez lógica y la irracionalidad de su sustentación como justificación del conocimiento. La inducción, como proceso lógico destinado a justificar racionalmente una teoría mediante la verificación, debe ser desechada. La explicación de la práctica científica, de modo que sea racional, tiene sentido si ésta se asume como la búsqueda de regularidades, formulando leyes sobre ellas que pueden ser refutadas mediante una experiencia que desacredite el contenido proposicional de la teoría. Esto se debe a que sólo la refutación de una teoría puede ser inferida válidamente de datos empíricos, inferencia que es meramente deductiva. En términos sencillos: la universalidad no es sostenible lógicamente si existe una excepción que no puede explicar la teoría. ${ }^{47}$

De esta forma, para Popper, lo que caracteriza a la práctica científica no es la verificación de teorías, sino que la elaboración de conjeturas y su sometimiento a prueba. Esta teoría tiene la consecuencia de admitir la provisoriedad del conocimiento, ya que el status actual del conocimiento depende de la inexistencia de un experimento que demuestre su falsedad. El conocimiento sólo será una conjetura corroborada mediante experimentos refutatorios fracasados, pero en caso alguno será conocimiento justificado o verificado, en los términos sostenidos por el Positivismo Lógico. De esta forma, el conocimiento no será por acumulación, como era sostenido previamente, sino que por sustitución, mediante la formulación de conjeturas y su eventual refutación.

\subsubsection{El programa historiográfico de las ciencias de Thomas Kuhn}

Tanto el Positivismo Lógico como el falsacionismo de Popper pretendían realizar una justificación con carácter trascendental del conocimiento o su refutación. La teoría de Kuhn, a diferencia de las anteriores, se caracteriza por pretender realizar una descripción verosímil de la práctica científica. Para este autor, las teorías precedentes son inverosímiles desde el punto de vista de lo que realmente realizan los científicos, ya que no describen la practica de los científicos al ejercer su profesión. Los científicos no trabajan para verificar o falsear teorías, sino que para adquirir nuevo conocimiento práctico, explicar fenómenos incomprensibles, etc. Por ello propone una teoría descriptiva de la historia de la actividad científica. Kuhn describe la historia de las ciencias bajo las nociones de paradigma y

\footnotetext{
${ }^{45}$ POPPER, Conjeturas y Refutaciones, cit. nota $\mathrm{n}^{\circ}$ 42, p. 50.

${ }^{46}$ Esta es la respuesta que Popper le da al tradicional problema de la demarcación, entendiendo por ésta la distinción entre las teorías que son científicas de aquellas que no lo son.

${ }^{47} \mathrm{La}$ incapacidad de la teoría para explicar la excepción es también conocido como una anomalía.
} 


\section{Polít. crim. Vol. 14, No 27 (Julio 2019), Art. 16, pp. 549-598 [http://politcrim.com/wp-content/uploads/2019/06/Vol14N27A16.pdf]}

revolución. ${ }^{48}$ Para este autor, 'paradigma' es una noción global que comprende todos los compromisos compartidos por un grupo científico, mientras que el grupo científico esta constituido por el grupo de personas que comparten el mismo paradigma. ${ }^{49}$ En sus escritos posteriores ${ }^{50}$ Kuhn intenta precisar sus vagos términos sobre paradigmas, aportando la noción de 'matriz disciplinar' la cual contiene entre sus componentes más relevantes a (i) las generalizaciones simbólicas, (ii) los modelos y (iii) soluciones paradigmáticas a problemas concretos. Es decir, las teorías contienen bastante más que los meros enunciados observacionales, apartándose en ello claramente de lo sostenido previamente por el Positivismo Lógico. Para este autor, el cambio teórico es de carácter revolucionario. La revolución viene dado por la sustitución de un paradigma por otro. Sin embargo, la sustitución de un paradigma por otro no sería el reflejo de una refutación racional del paradigma, en el sentido popperiano, dado que los paradigmas se caracterizan por contener tanto a la teoría como a su método evaluativo, lo que los convierte en inconmensurables entre sí, de modo que lo racional bajo un paradigma, puede ser, por ejemplo, un simple prejuicio bajo el otro. Así "un cambio de paradigma implica cambios en las normas que rigen los problemas, los conceptos y las explicaciones permisibles". ${ }^{51}$ Esta inconmensurabilidad de paradigmas trae como consecuencia que el cambio teórico no puede ser justificado racionalmente, ni menos ser calificado por ello como un progreso. Kuhn describe la práctica científica distinguiendo dos períodos, ciencia normal u ordinaria y ciencia extraordinaria. El trabajo desarrollado en un período de ciencia normal, que es la regla general, se caracteriza por la investigación de la comunidad científica bajo el paradigma unívocamente compartido por ellos, en este período el progreso científico es por acumulación. Por su parte, el trabajo científico desarrollado bajo el período de ciencia extraordinaria se caracteriza por la dualidad de paradigmas en disputa, el obsoleto y el nuevo, en que el conocimiento es adquirido por sustitución de paradigmas.

La perspectiva asumida por Kuhn para realizar la descripción de la práctica científica es la propia de un observador. Esta perspectiva -asumida por decisión metodológica- implica no tomar en consideración la pretensión de validez (racionalidad) que los propios partícipes de la práctica realizan con su argumentación científica. ${ }^{52}$

\footnotetext{
${ }^{48}$ El libro fundamental es KUHN, Thomas La estructura de las revoluciones científicas, Fondo de Cultura Económica, 1971.

${ }_{49}$ Así descrita constituye una delimitación evidentemente circular. La consecuencia directa de esta demarcación de teorías que son aceptadas como científicas, es erigir un criterio elitista sin prever un control racional. Sólo es teoría científica lo que el grupo científico acepte como tal, reduciendo la pretensión de racionalidad de las teorías científicas a mera convención.

${ }^{50}$ KUHN, Thomas, "Segundos pensamientos sobre paradigmas", Madrid: Tecnos, 1978.

${ }^{51}$ SHAPERE, Dudley. "Significado y cambio científico", en Ian Haking, Revoluciones Científicas. Fondo de Cultura Económica. México. 1985, pp. 58 - 115, p. 107.

${ }^{52}$ La crítica habitual a esta descripción es que los científicos pretenden realizar una explicación correcta y racional de los hechos que describen, y no sólo una explicación aceptada por sus pares. Esto redunda en que el cambio de paradigma constituye una decisión pretendidamente racional para los partícipes, es decir, fundada en buenas razones, y no el cambio de un paradigma que simplemente ha sido abandonado por falta de convicción.
} 


\subsubsection{La metodología de los programas de investigación científica de Imre Lakatos}

Imre Lakatos, discípulo de Popper, plantea su teoría como una superación del falsacionismo popperiano, ${ }^{53}$ denominándola como falsacionismo sofisticado. La renovación de la teoría se basa principalmente en la inclusión del componente temporal, Lakatos entra en la discusión cuando domina el historicismo convencionalista de Kuhn y se retira el racionalismo. Esta teoría asume una postura racional ante el tradicional problema de la demarcación. Sin embargo, para el falsacionista sofisticado, la demarcación de teorías científicas no viene dado por su base empírica, sino que una "teoría es aceptable o científica sólo si tiene un exceso de contenido empírico corroborado con relación a su teoría predecesora (o rival); esto es, sólo si conduce al descubrimiento de hechos nuevos". 54 Para este autor, al igual que para Kuhn, las teorías científicas tienen un contenido más amplio que los meros enunciados observacionales, único contenido identificado por las teorías racionalistas previas. Así, los programas consisten "en reglas metodológicas: algunas nos dicen las rutas de investigación que deben ser evitadas (heurística negativa), y otras, los caminos que deben seguirse (heurística positiva)". ${ }^{55}$ La heurística negativa del programa consiste en su centro firme que, por decisión metodológica, no permite refutación. En cambio, la heurística positiva consiste en un conjunto, parcialmente estructurado, de sugerencias o pistas sobre como cambiar y desarrollar las versiones refutables del programa de investigación, es llamado también cinturón protector, el cual esta constituido por hipótesis auxiliares, condiciones iniciales y sugerencias de investigación que protegen de la refutación al núcleo firme.

Para este autor, el análisis de las teorías puede realizarse en un sentido sincrónico (estático) y en un sentido diacrónico (dinámico). Como se puede apreciar, la gran novedad del falsacionismo sofisticado, frente al "ingenuo" de Popper, es el análisis diacrónico. Este análisis permite dar verosimilitud al falsacionismo, en tanto permite justificar la mantención de un programa que puede ser temporal y parcialmente refutado, tal como se evidencia en la práctica científica. A diferencia de Popper, en la teoría de Lakatos la refutación no es realizada por la contrastación de la teoría con la naturaleza, sino que es dada por la inconsistencia de la teoría refutada (también denominadas anomalías), de acuerdo a lo demostrado por otras teorías que tengan un mayor contenido proposicional. Los programas pueden intentar solucionar una anomalía mediante la formulación de hipótesis ad-hoc. Sin embargo, la existencia de ellas ya evidencia la pérdida de heurística positiva del programa (calificándose por ello como regresivo) al ser incapaz de anticipar y solucionar adecuadamente nuevos problemas teóricos. Por lo mismo, la refutación no es instantánea mediante un experimento crucial, sino que es retrospectiva y temporalmente diferenciable, de modo que sólo ex post es posible determinar cuál fue el experimento que determinó el abandono de la teoría.

\footnotetext{
${ }^{53}$ Así expone en primera persona: “Trataré de exponer y de fortalecer este enfoque popperiano, más sólido que el anterior y que, según pienso, puede ser inmune a las críticas de Kuhn y presentar las revoluciones científicas como casos de progreso racional y no de conversiones religiosas" LAKATOS, Imre. La metodología de los programas de investigación científica. Alianza Editorial: Madrid, España, 1983, pp. 17 133, p. 19.

${ }^{54}$ LAKATOS, La metodología de los programas de investigación científica, cit. nota n ${ }^{\circ}$ 53, p. 46

${ }^{55}$ LAKATOS, La metodología de los programas de investigación científica, cit. nota n ${ }^{\circ}$ 33, p. 65.
} 


\section{Polít. crim. Vol. 14, № 27 (Julio 2019), Art. 16, pp. 549-598 [http://politcrim.com/wp-content/uploads/2019/06/Vol14N27A16.pdf]}

De esta forma, es racional mantener un programa de investigación que presente alguna refutación singular, pero que todavía en su conjunto no se demuestre como irreversiblemente regresivo. Esto se debe a que la evaluación de la racionalidad de la mantención de la investigación bajo un programa se determina por su propia historia, la acumulación de anomalías y la presentación de un programa progresivo alternativo desencadenará el abandono de un programa para la asunción de otro. Por otra parte, en forma análoga a la noción de ciencia normal y ciencia extraordinaria de Kuhn, Lakatos propone la noción de ciencia madura, entendiendo por esta "programas de investigación que anticipan no sólo hechos nuevos sino también, y en un sentido importante, teorías auxiliares nuevas: La ciencia madura, al contrario del pedestre ensayo y error, tiene poder heurístico". 56

La teoría de Lakatos, a diferencia de Kuhn, asume la perspectiva del partícipe en la descripción de su práctica. Con ello da cuenta y se hace cargo de la pretensión de racionalidad que tienen las teorías científicas, manteniendo un potencial crítico, aunque claramente más modesto que el de las teorías racionalistas previas, en la medida que adjudicación de racionalidad de una postura teórica o de el programa teórico que debe ser seguido debido a su corrección, no puede ser realizado inmediatamente y en cualquier momento, con prescindencia de su historia. En sus propios términos, Lakatos afirma "yo miro la continuidad de la ciencia a través de unas gafas popperianas. Donde Kuhn ve paradigmas, yo veo también programas de investigación racionales". 57

Finalmente, Lakatos no sólo se limita a desarrollar una metodología de los programas de investigación científica, sino que propone un método histórico de adjudicación de racionalidad entre las diversas metodologías. ${ }^{58}$ Propone un falsacionismo como metacriterio de adjudicación entre las diversas metodologías de evaluación científica, de modo que "todas las metodologías funcionan como teorías o programas de investigación historiográficos (o meta-históricos) y pueden ser criticadas en las reconstrucciones racionales que originan", ${ }^{59}$ la historia corrobora o refuta la metodología propuesta. Con otras palabras, Lakatos propone un criterio histórico para evaluar racionalmente a las teorías rivales y a las metodologías teóricas rivales de evaluación. Sosteniendo en ambos niveles la pretensión de racionalidad inmanente a ambos discursos teóricos.

\subsection{La pertinencia de las nociones de paradigma y programa de investigación científica para las comprensión y evaluación de las teorías dogmáticas}

Una aproximación al problema de la cientificidad del derecho a partir de una concepción de ciencia y conocimiento científico propio del Positivismo Lógico destaca las diferencias que existen entre dicha práctica y la dogmática jurídica. El objeto de referencia, la metodología empleada y la pretensión de validez del conocimiento generado por sus discursos son diversos e inconmensurables. El objeto de referencia, regularidades empíricas para las

\footnotetext{
${ }^{56}$ LAKATOS, La metodología de los programas de investigación científica, cit. nota n 53, p. 117.

${ }^{57}$ LAKATOS, La metodología de los programas de investigación científica, cit. nota n 53, p. 119.

${ }^{58}$ LAKATOS, La metodología de los programas de investigación científica, cit. nota $\mathrm{n}^{\circ} 53$, pp. 158 y ss.

${ }^{59}$ LAKATOS, La metodología de los programas de investigación científica, cit. nota n 53, p. 159.
} 


\section{SCHURMANN, Miguel “¿Es científico el discurso elaborado por la dogmática jurídica? \\ Una defensa de la pretensión de racionalidad del discurso dogmático elaborado por la ciencia del derecho penal".}

teorías científicas, y una creación cultural por la otra, para el sistema jurídico. El método empleado, la verificación de hipótesis mediante el método científico versus la interpretación de normas bajo la teoría del método jurídico. Finalmente, una pretensión de verosimilitud o verdad de sus postulados en contraposición a enunciados teóricos que llevan implicados una pretensión de corrección, hacen que ad initio no quepa analizar las similitudes de ambos discursos teóricos. ${ }^{60}$ Sin embargo, un análisis comparativo a partir de las contribuciones teóricas posteriores al positivismo lógico entrega resultados diversos. Para evaluar la racionalidad o la cientificidad de la dogmática jurídica, no solamente se deben analizar los enunciados elaborados por una y otra práctica, sino que principalmente evaluar sus estándares de racionalidad y decisiones metodológicas, todos ellos contenidos bajo la noción de paradigmas (matriz disciplinar) en la teoría de Kuhn o de programas de investigación científica, en la de Lakatos. Es decir, no solo se debe evaluar el lenguaje de ambos discursos, sino que el metalenguaje de ambos, en donde la pretensión de racionalidad de la práctica es tematizado.

Tal como se analizó previamente, ${ }^{61}$ la dogmática penal alemana se ha preocupado especialmente de establecer estándares a su práctica, de modo de diferenciar qué cuenta como teoría científica del derecho penal y qué discurso no alcanza dicho umbral. Esto es equivalente a lo que en la filosofía de las ciencias se denomina como el problema de la demarcación. Los criterios que establece la dogmática jurídica no se refieren primariamente a la aceptación de la comunidad, ${ }^{62}$ sino que a la satisfacción de determinados requisitos argumentativos de las teorías propuestas. Las teorías dogmáticas llevan implícita una pretensión de corrección, en donde más allá de la conciencia y tolerancia de teorías rivales, las teorías se plantean como la respuesta correcta a un determinado problema teóricointerpretativo. Esta pretensión de corrección y simultánea tolerancia a la existencia de teorías rivales se demuestra en el planteamiento de las teorías dogmáticas, las cuales suelen sostenerse en oposición a las teorías rivales, polemizando con ellas e intentando demostrar las ventajas teóricas de la propuesta propia frente a las otras postuladas. Ellas son planteadas bajo la asunción de que su tesis interpretativa -debido a las razones en que se funda- es la correcta para la comprensión y aplicación del sistema jurídico, en análogos términos como pretende una teoría científica en el ámbito empírico ser una descripción

\footnotetext{
${ }^{60}$ Una comparación de estas características es comúnmente formulada por quienes implícita o explícitamente asumen alguna versión de monismo metodológico, en donde el método de las ciencias naturales y el tipo de conocimiento que ellos proveen constituye el paradigma evaluativo de toda práctica cognoscitiva. Ver por ejemplo BERNASCONI RAMÍREZ, "El carácter científico" cit. nota ${ }^{\circ} 5$, pp. 15 y ss. quien es escéptico de la viabilidad de esta vía argumentativa para sostener el carácter científico de las teorías dogmáticas.

${ }^{61}$ Ver supra 2.2

${ }^{62}$ Una discrepancia parcial podría encontrarse en la opinión de Schünemann sobre la evaluación de las teorías dogmáticas, quien sostiene que la calidad de las publicaciones dogmáticas no solo se encuentra garantizado por la posibilidad de que la comunidad dogmática pueda analizar y eventualmente criticar la propuesta teórica, sino que también por la satisfacción del requisito profesional en el ámbito académico del escrito de habilitación, el que prueba la capacidad del dogmático para integrarse al diálogo científico. Sin embargo, dicho criterio tiene claramente un carácter auxiliar en su presentación. SCHÜNEMANN, "Standpunkte der deutschen Strafrechtslehrer", cit. nota n 4, p. 304.
} 


\section{Polít. crim. Vol. 14, No 27 (Julio 2019), Art. 16, pp. 549-598 [http://politcrim.com/wp-content/uploads/2019/06/Vol14N27A16.pdf]}

verdadera de acontecimientos en el mundo y de predecir eventos futuros que compartan las características cruciales afirmadas por la teoría. ${ }^{63}$

Una comparación ahora referida al nivel de los fundamentos y metodología adoptados por los programas de investigación científicos y dogmáticos requiere previamente excluir la preconcepción de los mismos por parte del Positivismo Lógico, dado que bajo dicha concepción se excluyen estos ámbitos de la racionalidad, en tanto no constituyen enunciados verificables experimentalmente. Tal como lo sostuvo Habermas formulando su célebre crítica a una racionalidad reducida para las ciencias empíricas, la tesis de que solo las teorías empíricas son racionales, en tanto verificables mediante su confrontación con el mundo, implica una reducción inadmisible de la racionalidad teórica. Para refutar esta tesis, toma precisamente como ejemplo ese aspecto especialmente sensible para la metodología científica, los estándares evaluativos y la metodología de las ciencias experimentales, ya que si bien éstas son la base de las teorías empíricas (racionalmente justificables de acuerdo al Positivismo Lógico), la base misma de la teoría no es justificable de la misma forma, lo que conllevaría a que toda la práctica científica sería irracional. ${ }^{64}$ Sin embargo, los estándares y decisiones metodológicas sí son discutibles racionalmente, en el ámbito de una racionalidad comprensiva. El situar a la comprobación empírica como método para evaluar la corrección de una teoría, no constituye un requisito necesario, sino que es dependiente del estándar de comprobación que se decida racionalmente para las teorías. Así "la base experimental de las ciencias estrictas no es independiente de los estándares que esas mismas ciencias aplican a la experiencia", ${ }^{65}$ porque la experiencia es un método de comprobación entre muchos otros posibles. La decisión sobre cuál es el método de refutación o verificación de una teoría debe ser justificable racionalmente, para que la teoría científica -como producto y aplicación de ella- también lo sea. ${ }^{66}$

\footnotetext{
${ }^{63}$ Por cierto la cercanía entre teorías científicas y dogmáticas podría ser mayor si lo que se sostiene es que la función de estas últimas se circunscribe a la anticipación de cómo será realmente resuelto un caso (y no cómo debe ser resuelto de acuerdo a criterios de corrección), equiparándose a la capacidad predictiva que postulan las teorías científicas para el ámbito empírico. Decididamente en este sentido NÚÑ̃Z VAQUERO, Álvaro. "Sobre 'algunos argumentos a favor de una ciencia jurídica interpretativa' de Aldo Schiavello", Doxa Cuadernos de Filosofía del Derecho $\mathrm{N}^{\mathrm{o}}$ 38, 2015, pp. 501-524. Disponible en http://doxa.ua.es/article/view/2015-n38-sobre-algunos-argumentos-a-favor-de-una-ciencia-juridica-

interpretativa-de-aldo-schiavello [visitado el 22.03.2018]. p. 508 y ss. Para una crítica de una comprensión del objeto de la dogmática en este sentido ver infra 5.1 .

64 A partir de ello, Habermas esboza una teoría demarcacionista de las teorías científicas: "como empíricamente verdaderas se consideran entonces todas las hipótesis que pueden guiar una acción controlada por el éxito, sin haberse visto problematizadas hasta ahora por fracasos insistentemente buscados experimentalmente". La definición es dependiente de su noción de acción instrumental y sin perjuicio de la evolución que tuvo su teoría de la verdad, la que no viene al caso desarrollar. HABERMAS, Jürgen. "Una polémica (1964): Contra el racionalismo disminuido en términos positivistas”. En: La lógica de las ciencias sociales, Trad.: JIMÉNEZ REDONDO, Manuel . Madrid: Tecnos, pp. 19 - 78, p. 54.

${ }^{65}$ HABERMAS, "Una polémica (1964)", cit. nota n 64, p. 47.

${ }^{66}$ Como respuesta a esta objeción ha sido afirmado que la decisión que antecede a la aplicación de su método es irracional, dado que constata la imposibilidad de justificarse deductivamente. Sin embargo, el propio planteamiento de la teoría desmiente esta respuesta, dado que el método de falsación de teorías es extensamente justificado dentro de la práctica científica, en términos de argumentación crítica, de modo que su pretensión implícita no es imponer o dejar en plena libertad la elección del estándar de evaluación de teorías, sino que justificar la aplicación del esquema que se propone como la única o mejor decisión
} 


\section{SCHURMANN, Miguel “¿Es científico el discurso elaborado por la dogmática jurídica? Una defensa de la pretensión de racionalidad del discurso dogmático elaborado por la ciencia del derecho penal".}

Por cierto, las teorías y las decisiones metodológicas sobre éstas pueden ser analizadas críticamente. Así, la dimensión que decide la validez de una teoría es susceptible, a su vez, de crítica. La crítica es la práctica racional que supone la aportación de argumentos en pro o en contra de una postura teórica determinada. La argumentación crítica, por su parte, se distingue de la mera deducción, porque permite la crítica de los presupuestos conforme a los que procede, es decir, la crítica nunca puede atenerse a condiciones que la limiten. En palabras de Habermas "la crítica, al establecer un nexo racional entre actitudes y argumentos, constituye, justamente, la dimensión comprensiva o global de la ciencia. El saber teórico en modo alguno puede sernos más seguro que el crítico". ${ }^{67}$ Esta es la dimensión de racionalidad comprensiva que, aunque incapaz de una fundamentación última buscada por el Positivismo Lógico, se despliega en un círculo de autojustificación reflexiva que permite aceptar a una determinada teoría como racional bajo determinadas condiciones. ${ }^{68}$

Si se realiza un análisis comparativo de lo que, por un parte, la teoría de Lakatos formula como programa de investigación científico -asumiendo la pretensión de racionalidad de los fundamentos y premisas teóricas y metodológicas que constituyen el núcleo firme del programa- y, por la otra, la autocomprensión de los estándares de cientificidad postulados por la dogmática jurídico penal y su desarrollo histórico, las similitudes se reflejan con mayor facilidad, ${ }^{69}$ como se verá infra 5.3. Sin embargo, ello no le otorga necesariamente el carácter de científico a un paradigma dogmático, para ello debe clarificarse previamente cuáles son las pretensiones de validez de su discurso, esto es, en qué condiciones una teoría dogmática puede ser calificada como correcta y el conocimiento que entrega como válido, en la medida que se sostenga, como aquí, que la calificación de científica de una práctica implica la afirmación de una pretensión de racionalidad en el discurso. Así, una vez indagado en el parámetro evaluativo con el que se pretende comparar la dogmática, ahora es necesario indagar y delimitar el objeto de comparación, cuáles son las pretensiones de validez propias del derecho en general y del discurso dogmático en particular, para luego delimitar qué constituye una teoría dogmática.

metodológica. La falacia que lleva inserta la respuesta es usualmente denominada como contradicción performativa.

${ }^{67}$ HABERMAS, “Una polémica (1964)", cit. nota n 64, p. 61.

${ }^{68}$ La argumentación crítica se distingue de la deductiva porque trasciende la dimensión de la conexión lógica de enunciados. Una decisión valorativa o metodológica, cualquiera sea el ámbito en que se plantee, puede apoyarse o debilitarse con argumentos, "puesto que los argumentos aducidos en pro o en contra, no guardan ninguna relación estrictamente lógica con los enunciados que expresan la aplicación de estándares, sino sólo una relación de motivación racional, las discusiones metateóricas pueden incluir también enunciados empíricos”. HABERMAS, “Una polémica (1964)”, cit. nota n 64, p. 57.

${ }^{69}$ Un interesante ejercicio que adopta esta perspectiva para evaluar la racionalidad y corrección de las teorías dogmáticas en el ámbito penal formuladas por Roxin y Jakobs, sin comprometerse fuertemente con la corrección del aparato teórico evaluativo (al calificar el uso del aparato conceptual de Lakatos como instrumental, con fines estéticos), es el realizado en WILENMANN VON BERNATH, Javier. “Conocimientos especiales en la dogmática jurídico-penal y teoría de las ciencias", Revista de Estudios de la

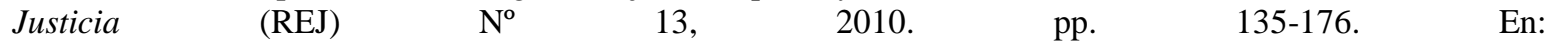
https://revistaderechoambiental.uchile.cl/index.php/RECEJ/article/view/15247/15660 [visitado el 22.03.2018]. 


\section{Polít. crim. Vol. 14, № 27 (Julio 2019), Art. 16, pp. 549-598 [http://politcrim.com/wp-content/uploads/2019/06/Vol14N27A16.pdf]}

\section{Las pretensiones de validez y el problema de la demarcación en el ámbito de la dogmática jurídica}

El objetivo de este apartado es revisar analíticamente el discurso dogmático, dando cuenta de su especificidad como proceso argumentativo, de modo de indagar cuáles son las pretensiones de validez insertas en sus enunciados teóricos, cómo ellas se desempeñan en la discusión desarrollada en la dogmática jurídica y qué características deben poseer dichos enunciados o grupos de enunciados para ser calificados como una teoría dogmática. Para emprender dicho camino es necesario caracterizar la particularidad del discurso teóricointerpretativo sobre el derecho vigente, la relación con su objeto y los tipos de enunciados que son elaborados para dar cuenta de él, de modo de presentar adecuadamente tanto la práctica, entendiendo por tal tanto la delimitación de su objeto como la metodología empleada, así como de su pretensión de racionalidad asociada, de modo de evaluar en qué sentido puede ser (re)afirmada su cientificidad, tal como la sostienen los dogmáticos, o su especial forma de racionalidad, como podría ser sostenida por la filosofía del derecho.

El presupuesto del análisis de este apartado lo constituye la conclusión del anterior. Tal como la hermenéutica ${ }^{70}$ lo demostró, no existe solo un método válido para adquirir conocimiento. No es posible comprender ni dar cuenta adecuadamente de la práctica de la dogmática-jurídica sin dar cuenta a su vez de los conceptos y reglas que determinan dicha realidad social, es decir, asumir la perspectiva del partícipe. ${ }^{71}$ Solo adoptando dicha perspectiva puede describirse adecuadamente cómo funciona la dogmática jurídica y establecerse un parámetro de qué tipo de actividad puede ser calificada como tal. ${ }^{72}$

\footnotetext{
${ }^{70}$ Sobre la aproximación realizada por la hermenéutica como tradición metodológica alternativa ver VON WRIGHT, "Explanation and Understanding”, cit. nota ${ }^{\circ} 39$, pp. 28 y ss.

${ }^{71}$ Así entre otros SCHIAVELLO, Aldo. "Algunos argumentos a favor de una ciencia jurídica interpretativa", Doxa -Cuadernos de Filosofía del Derecho $\mathrm{N}^{\circ}$ 37, 2014, pp. 193 - 217. Disponible en http://doxa.ua.es/article/view/2014-n37-algunos-argumentos-a-favor-de-una-ciencia-juridica-interpretativa [visitado el 22.03.2018], p. 198.

${ }^{72}$ Recurriendo a una falsa analogía para explicar el presupuesto teórico de asunción de la posición del partícipe de la práctica (afirmando que es equivalente a la afirmación de que solo quien juega fútbol puede dar cuenta adecuadamente de qué implica el deporte, o que solo una víctima de terrorismo puede entender lo que implica, etc.), niega dicha necesidad Núñez, en NÚÑEZ VAQUERO, "Sobre 'algunos argumentos", cit. nota $\mathrm{n}^{\circ}$ 63, pp. 511 y ss. Lo que revela la selección de los ejemplos por parte de Núñez es su incomprensión del significado del requerimiento teórico. Asumir la perspectiva del partícipe implica comprender de acuerdo a las reglas y conceptos de la práctica según los partícipes y no meramente de acuerdo a una observación externa. Así, en el ejemplo del fútbol, implica conocer las reglas del fútbol y atribuirle sentido a las tácticas y esfuerzos por anotar un gol u obtener una victoria. Desde la perspectiva del observador podríamos dar cuenta de un grupo de personas corriendo tras de un balón. En el ejemplo del terrorismo, la comprensión del fenómeno requiere ver en ella algo más que la suma de hechos violentos aislados o una intencionalidad destinado a repetirlos, es decir, un sentido aglutinador que refuerza el terror que infunde en la población. Para el caso del derecho implica dar cuenta del sentido de obligatoriedad del derecho (más allá del mero acaecimiento de un mal en el evento de que se realice determinada acción), su pretensión de racionalidad (que lo diferencia de un juicio popular o divino), entre otras características. Por cierto ambas perspectivas son válidas y son simplemente distintos puntos de vista, lo relevante es asumir que la autocomprensión de la práctica no puede ser descrita adecuadamente sin su propio punto de vista. Con claridad da cuenta del problema filosófico relacionado con la asunción de la perspectiva del observador Wittgenstein, cuando se pregunta ¿cómo podría un observador (que desconoce las reglas de un juego) determinar cuándo un jugador ha realizado una movida correcta o ha infringido las reglas del juego). WITTGENSTEIN, Ludwig.
} 


\section{SCHURMANN, Miguel “¿Es científico el discurso elaborado por la dogmática jurídica? Una defensa de la pretensión de racionalidad del discurso dogmático elaborado por la ciencia del derecho penal".}

\subsection{La orientación práctica de la dogmática y su vinculación con el derecho vigente}

Este tipo de discurso se caracteriza por ser institucionalmente ligado, toda vez que se rige por ciertas reglas del juego caracterizadas por un corte en el proceso de justificación de sus premisas, a través de criterios procedimentales de validez que, en último término, compensa los déficits de racionalidad del derecho vigente por medio de argumentos políticos, radicados especialmente en la legitimidad del procedimiento democrático de generación normas. Esto es lo que suele denominarse como actitud dogmática frente al derecho. ${ }^{73}$ Las disposiciones vigentes del sistema jurídico constituyen el inicio de toda cadena argumentativa ${ }^{74} \mathrm{y}$, al mismo tiempo, un límite a la validez de los enunciados dogmáticos. Es decir, este tipo de discurso se caracteriza por su objeto, el derecho vigente, sobre el cual articula un discurso propio que se trata de imponer como la mejor comprensión del derecho vigente, respondiendo a una tensión que es inmanente a la auto comprensión de la práctica de la dogmática, entre corrección y verosimilitud de la teoría con el derecho vigente. ${ }^{75}$ Así, mientras una teoría dogmática que no se haga cargo del derecho vigente es una teoría incorrecta, un discurso que se limite a narrar el derecho vigente es irrelevante, no pudiendo contar como teoría dogmática. ${ }^{76}$ Dicha irrelevancia

Philosophische Untersuchungen. Bibliothek Suhrkamp, 7 Edición, 2015, p. 49. (Existe versión en español: WITTGENSTEIN, Ludwig, Investigaciones filosóficas, Editorial Trotta, 1. Edición. 2017).

${ }^{73}$ La idea tradicional que envuelve la noción de aceptación dogmática por el Derecho es recogida por Celis al definirla como considerar a las leyes como auténticas, válidas, sin ser cuestionadas en dicho sentido. Ello no implica por cierto que el jurista asuma necesariamente la corrección material de la norma, ello es contingente. CELIS DANZINGER, "Relaciones entre Filosofía del Derecho, Ciencia Jurídica y Teoría del Derecho", cit. nota $\mathrm{n}^{\circ} 9$, p. 122. Una revisión de las posibles nociones implicadas en la idea de aceptación dogmática del derecho se encuentra en NÚÑEZ VAQUERO, "Dogmática jurídica", cit. nota $\mathrm{n}^{\circ}$ 2, p. 255. Sin embargo Núñez renuncia a dar cuenta de la especificidad del razonamiento dogmático por su referencia necesaria al derecho vigente, diluyendo dicha característica en una aceptación "completamente contingente, dependiendo de cada cultura jurídica y de cada dogmático" (p. 259). El error de la tesis de Núñez radica en asumir que la eventual crítica del derecho vigente por parte del dogmático, mediante por ejemplo argumentos de lege ferenda, obsta a este reconocimiento. Sin embargo, es precisamente la distinción de argumentos de lege lata y lege ferenda y la eventual crítica al derecho positivo la que lleva implícita su reconocimiento como derecho vigente. El posicionamiento crítico del dogmático frente al derecho vigente implica lógicamente su reconocimiento como punto de partida argumentativo.

${ }^{74}$ ATIENZA, Manuel. "La dogmática jurídica como tecno-praxis", en: NÚÑEZ, Álvaro (Coord.), Modelando la ciencia jurídica. Palestra Editores, Lima, 2014. pp. 169 - 196, p. $170 . \quad$ En: https://archivos.juridicas.unam.mx/www/bjv/libros/8/3825/10.pdf [visitado 22.03.2018].

${ }^{75}$ Esta ligazón institucional es asumido por Luhmann como una condición de la práctica, pero no como su característica práctica definitoria. Para Luhmann la dogmática conceptualmente se caracteriza por la prohibición de la negación: la no-negabilidad de los puntos de partida de la cadena de argumentación, lo que en el caso de la dogmática jurídica se ve reflejado en la falta de cuestionamiento a la validez del derecho vigente. Sin embargo, lo que caracterizaría a la dogmática es su función positiva, esto es, no el encadenamiento de la argumentación, sino que lo contrario, el aumento de las libertades en el trato del derecho. La dogmática permite la reproducción de dudas, el aumento de las inseguridades soportables. Estas inseguridades son las compatibles con dos exigencias centrales del sistema jurídico: la vinculación con las normas jurídicas y con la necesidad de tomar una decisión en caso de conflictos jurídicos. LUHMANN, Sistema jurídico, cit. nota ${ }^{\circ} 14$, pp. 27 y ss.

${ }^{76}$ Así también en VERGARA BLANCO, "Teoría del Derecho, Filosofía del Derecho y Doctrina Jurídica", cit. nota $\mathrm{n}^{\circ} 3$, p. 639, quien expresamente allí afirma que "pues si un libro sólo ofrece una sencilla y básica sistematización normativa, a partir de una básica interpretación (más o menos literalista), usualmente no 


\section{Polít. crim. Vol. 14, No 27 (Julio 2019), Art. 16, pp. 549-598 [http://politcrim.com/wp-content/uploads/2019/06/Vol14N27A16.pdf]}

radica no solo en la falta de contenido informativo adicional al ya previsto por las disposiciones legales, sino que principalmente en la falta de cumplimiento de las funciones comúnmente atribuidas a la dogmática. Entre otras falencias, una re-narración del derecho vigente no contribuye a sistematizar e integrar el ordenamiento jurídico mediante la formación de grupos de casos tendientes a aplicar uniformemente el Derecho y así satisfacer el ideal de coherencia atribuido al sistema jurídico. ${ }^{77}$

Como toda argumentación jurídica, la dogmática realiza enunciados de diversa naturaleza, tanto constatativos como normativos. ${ }^{78}$ Así, por una parte, realiza enunciados constatativos, por ejemplo, la acción X se encuentra permitida en el derecho de Y. Por otra parte, en el desempeño de su labor de sistematizar e integrar el ordenamiento jurídico, es usual que la dogmática desarrolle enunciados prescriptivos bien para satisfacer ideales de justicia o solucionar defectos lógicos, de la forma 'por las razones esbozadas, la norma aplicable para el caso $\mathrm{N}$ es $\mathrm{X}$ y no $\mathrm{Y}$ '. La variedad de enunciados se debe, principalmente, a la diversidad de funciones que asume la dogmática en el ámbito jurídico. ${ }^{79}$ La relación que tiene la dogmática con su discurso objeto, el derecho vigente, es similar a lo que en Filosofía del lenguaje equivale a la distinción entre 'enunciado' y su 'significado'. ${ }^{80}$ En Derecho, la distinción convencional se presenta entre 'disposiciones' y 'normas' ${ }^{81}$ entendiendo por las primeras las enunciados fijados en textos autoritativos, mientras que por las segundas se entiende a la disposición interpretada. El derecho vigente no sólo constituye el objeto de referencia, sino que también el límite o cierre en el proceso de justificación externa de las premisas normativas, es decir, la apertura a la crítica de sus enunciados reconoce como límite a las disposiciones establecidas autoritativamente, ya que éstas no pueden ser desestimadas válidamente por el dogmático, y su interpretación no puede situarse más allá del ámbito del sentido literal posible de la disposición. ${ }^{82}$

merece ser calificada de doctrina o dogmática, sino de un arte menor: como un mero texto de apoyo a los estudios legales o a la práctica forense".

${ }^{77}$ En la polémica suscitada entre SCHIAVELLO, “Algunos argumentos”, cit. nota n 71, p. 210 y NÚÑEZ VAQUERO, "Sobre 'algunos argumentos", cit. nota n 63, pp. 506 y ss. Núñez cuestiona la afirmación precedente, compartida por Schiavello, en orden a descartar por irrelevante una dogmática meramente descriptiva. Sin embargo, lo que Núñez no da cuenta al cuestionar dicha afirmación es que el objeto de análisis de la práctica cambia bajo su comprensión de la dogmática, ya no son las disposiciones del sistema jurídico, sino que las decisiones de los tribunales. Para una comprensión interpretativa (o hermenéutica) de la dogmática, las sentencias judiciales no constituyen principalmente un objeto autónomo de estudio, sino en cuanto postulan una interpretación del derecho que puede ser también objeto de eventual crítica. La propuesta de Núñez implica cambiar el objeto de estudio desde las disposiciones jurídicas a las decisiones de los tribunales, de modo de obtener información predictiva de sus futuras soluciones (ver infra 5.1).

${ }^{78}$ BASCUÑÁN RODRÍGUEZ, "Observaciones sobre la ciencia del derecho", cit. nota n 7, p. 18

${ }^{79}$ NÚÑEZ VAQUERO, "Dogmática jurídica", cit. nota n ${ }^{\circ}$ 2, p. 248

${ }^{80}$ Ver TUGENDHAT, Ernst. Introducción a la filosofía analítica. Editorial Gedisa. 2003. pp. 22 y ss.

${ }^{81}$ BASCUÑÁN RODRÍGUEZ, "Observaciones sobre la ciencia del derecho", cit. nota no 7, p. 20; WRÓBLEWSKY, Jerzy. Constitución y Teoría General de la Interpretación Jurídica, Madrid: Civitas, 1985, pp. 21 y ss.

${ }^{82}$ BASCUÑÁN RODRÍGUEZ, "Observaciones sobre la ciencia del derecho", cit. nota n ${ }^{\circ}$ 7, p. 22. Ello explica porque una teoría dogmática creada para otras disposiciones jurídicas no puede ser importada y simplemente propuesta para ser aplicada de forma irreflexiva. Ella deberá ser adaptada a las disposiciones locales y sólo podrá ser aplicada en la medida que contribuya a la racionalidad del Derecho en donde pretenda aplicación. 


\section{SCHURMANN, Miguel “¿Es científico el discurso elaborado por la dogmática jurídica? Una defensa de la pretensión de racionalidad del discurso dogmático elaborado por la ciencia del derecho penal".}

La dogmática se caracteriza por su orientación a la práctica, ya que ella debe ser capaz de elaborar enunciados en todo el espectro de perspectivas en las que se puede situar un individuo interesado por la solución correcta de un problema práctico-jurídico. La labor de la dogmática, al nivel de las aplicaciones pretendidas de la teoría, sólo puede ser sintetizada bajo la función de recomendar al juez la mejor solución posible conforme al derecho vigente, es decir, una argumentación de sentencia ferenda ${ }^{83} \mathrm{El}$ derecho se caracteriza por descargar al individuo de la responsabilidad de reflexionar sobre la racionalidad práctica de su decisión, su acción es lícita en base a lo permitido u ordenado por el Derecho. En este sentido, la labor del dogmático es la generalización e integración sistemática a la racionalidad de la administración de justicia, en la medida que, mediante teorías racionalmente articuladas, permita reducir el margen de arbitrariedad de los órganos de aplicación del Derecho, eliminando la imprevisibilidad de las decisiones ${ }^{84} \mathrm{o}$, en su defecto, ofreciendo un parámetro para criticarlas. En el desarrollo de esta labor, es común la elaboración de conceptos y sistemas de enunciados, ${ }^{85}$ los que buscan ligar las aplicaciones pretendidas de la teoría con los presupuestos teóricos y metodológicos a los que adscribe el interprete, de modo de satisfacer el requerimiento de corrección o coherencia interna previamente explicitado.

\subsection{La pretensión de rectitud del derecho vigente $y$, correlativamente, de la dogmática jurídica}

En el derecho vigente se encuentra de forma inmanente su pretensión de rectitud. La regulación jurídica se nos presenta con la pretensión de ser una respuesta racional a una necesidad de regulación del ámbito práctico, y no puro voluntarismo ${ }^{86}$. La dogmática, de forma correlativa, da cuenta de esta pretensión de rectitud y fundamenta sus decisiones en base a ella. Así, tanto el derecho como objeto, como las soluciones propuestas por la dogmática jurídica, se nos presentan con pretensiones de legitimidad. Es decir, la decisión normativa, no sólo es vinculante por la autoridad del derecho vigente, sino que por ser una regulación aceptable racionalmente, ya sea mediante su contenido o por referencia a su modo de creación, como la solución correcta a un problema práctico. ${ }^{87} \mathrm{Sin}$ embargo, es precisamente la pretensión de corrección que lleva inserta el discurso dogmático o parte de sus enunciados lo que genera mayores problemas de reconocimiento entre una parte de aquellos que analizan el valor científico de la dogmática. ${ }^{88}$ La pregunta que se encuentra

\footnotetext{
${ }^{83}$ BASCUÑÁN RODRÍGUEZ, “Observaciones sobre la ciencia del derecho”, cit. nota n 7, p. 19. Ello por cierto, no implica necesariamente previsibilidad, en tanto la judicatura se puede apartar de la respuesta correcta, y ser objeto de crítica por ello.

${ }^{84}$ Especialmente crítico de la posibilidad de alcanzar dicho objetivo mediante la formulación de teorías dogmáticas ver MATUS ACUÑA “Por qué citamos a los alemanes”, cit. nota n 8, pp. 325 y ss.

${ }^{85}$ NÚÑEZ VAQUERO, "Dogmática jurídica", cit. nota ${ }^{\circ}$ 2, p. 253

${ }^{86}$ Cabe recordar aquí el requisito establecido por Schünemann relativo a "que el carácter prohibido o mandatado de una conducta no puede ser producto de arbitrariedad, sino que de fundamentos racionales" ver supra 2.2. Así también VEGA, "Las calificaciones del saber jurídico”, cit. nota n 4, pp. 379 y ss.

${ }^{87}$ Una fundamentación de la pretensión de rectitud del Derecho se encuentra en HABERMAS, Jürgen. Facticidad y Validez, Trotta, 1998, Capítulo IV.

${ }^{88}$ Paradigmático a este respecto constituye la opinión de aquellos como Kelsen que sostienen que la dogmática debiese agotarse en enunciados descriptivos del contenido del Derecho, manteniendo una neutralidad valorativa, o del realismo jurídico, para quienes la labor de la ciencia jurídica se debiese abocar al
} 


\section{Polít. crim. Vol. 14, № 27 (Julio 2019), Art. 16, pp. 549-598 [http://politcrim.com/wp-content/uploads/2019/06/Vol14N27A16.pdf]}

tras este problema sería: ¿Es posible argumentar mediante enunciados prescriptivos de forma racional? Para abordar una respuesta a esta pregunta es necesario previamente hacer distinciones sobre el tipo de enunciado que es elaborado por el dogmático.

La distinción fundamental a este respecto es aquella elaborada por Klaus Günther, quien distingue entre el discurso de fundamentación de una regla y el discurso de aplicación de una regla a un caso concreto. Para una fundamentación discursiva de normas válidas se debe asegurar que una norma exprese un interés general en su seguimiento tomando en consideración los casos que regularmente se presentarán en la práctica. ${ }^{89}$ Por ejemplo, existen buenas razones para fundar una regla moral o jurídica que obligue a cumplir las promesas, ya que -en condiciones normales- existe un interés general en que las promesas sean cumplidas. Dichas razones deben ser desempeñadas discursivamente bajo condiciones ideales. ${ }^{90}$ La fundamentación de la validez general de una norma puede ser diferenciada de la justificación de la aplicabilidad de esa norma a un caso concreto, en donde ya no se discute su reconocimiento como norma válida, sino que la adecuación de su aplicación para dicho caso. ${ }^{91}$ Así, el deber general de cumplir las promesas puede colisionar contingentemente con otro deber, que se presenta como superior bajo determinadas circunstancias. ${ }^{92}$

El reconocimiento de supuestos en los cuales parece correcto moralmente incumplir una promesa poco relevante para cumplir otro deber moral que colisiona con él en el caso concreto, de modo que ambos no pueden ser cumplidos simultáneamente, implica aceptar que las normas válidas reclaman una aplicación prima facie, cuya aplicación definitiva depende una descripción íntegra de la situación y de la compatibilidad de dicha norma con todas las demás normas aplicables prima facie en dicha situación, lo que se suele conocer también como sistema jurídico del caso. Frente al ideal de racionalidad abstracta que sustenta una norma válida, se encuentra una pretensión de racionalidad diversa que gobierna la aplicación de reglas para un caso concreto, el ideal de un sistema coherente de

estudio de los factores que influyen en las decisiones judiciales y en determinar cuál es el derecho que los jueces realmente aplican y asumen como obligatorio. Sobre estos modelos de ciencia jurídica (en sentido amplio) ver NÚÑEZ VAQUERO, "Ciencia Jurídica", cit. nota n 9, pp. 610 y ss.

${ }^{89}$ GÜNTHER, Klaus. "Un concepto normativo de coherencia para una teoría de la argumentación jurídica", Doxa -Cuadernos de filosofía del Derecho № 17-18, Universidad de Alicante, España, 1995, pp. 271 - 301, p. 278.

${ }^{90} \mathrm{O}$ pueden ser desempeñadas, en la medida que la garantía argumentativa del enunciado con pretensiones de validez no siempre requiere ser desempeñado para ser reconocido por otros como racional. Ver infra nota 107

${ }^{91}$ Günther hace referencia a la situación ideal de una norma perfecta, como aquella en la cual no solo se encuentra fundamentada universalmente su validez, sino que también como aquella que se encuentra determinada para todo caso de aplicación. Dicho ideal sería posible en condiciones ideales, es decir, en una situación de fundamentación con tiempo y conocimiento ilimitados. Günther descarta la realización de este ideal no solo por cuestiones fácticas que lo imposibilitan, sino que también por resultar innecesario por pugnar con la preconcepción que tenemos sobre lo que significa fundar correctamente una norma, en oposición a aplicar correctamente una norma. GÜNTHER, "Un concepto normativo de coherencia", cit. nota $\mathrm{n}^{\circ}$ 89, pp. 278 y ss. Sin embargo, la imposibilidad de que una regla regule su propia aplicación también es lógico, como correctamente lo identifica posteriormente el mismo Günther. GÜNTHER, Klaus. "Critical Remarks on Robert Alexy's 'Special-Case Thesis”, Ratio Juris, Vol. 6 No. 2 July1993, pp. 143 - 156, p. 148.

${ }^{92}$ Así, el deber de cumplir una promesa poco relevante, puede ser preterido en caso de que colisione en un caso concreto con el deber de ayudar a un amigo (siguiendo el ejemplo empleado por Günther) o de proteger a alguien que se encuentra bajo nuestra custodia. 


\section{SCHURMANN, Miguel “¿Es científico el discurso elaborado por la dogmática jurídica? Una defensa de la pretensión de racionalidad del discurso dogmático elaborado por la ciencia del derecho penal”.}

normas válidas. ${ }^{93}$ Dicho ideal ha sido reconstruido también bajo la idea del principio de coherencia. ${ }^{94}$ Así, la norma que impone el deber de cumplir una promesa no recibe necesariamente aplicación cada vez que exista una promesa, sino que solo en cuanto una descripción íntegra de la situación no implique la adecuación de la aplicación de otra regla que tenga preeminencia en el caso concreto y que, contextualmente, implique no satisfacer el deber de cumplir lo prometido. Con ello, la afirmación de la aplicabilidad de una regla al caso concreto lleva inserto dos pretensiones de validez analíticamente diferenciables y susceptibles de ser desempeñadas discursivamente: (i) la afirmación de la existencia/validez de la regla; (ii) la afirmación de la adecuación de la regla para resolver el caso concreto. Si bien ambas pretensiones llevan implícita una garantía argumentativa, y que dicha garantía podría ser desempeñada en una argumentación contingentemente de forma indiferenciada, ellas se refieren a dos niveles que pueden y deben ser diferenciados analíticamente. Con otras palabras, si bien discursivamente puede ser cuestionada la validez y existencia de una regla que obligue a cumplir las promesas en general, generándose y desempeñándose un discusión racional sobre la fundamentación y/o validez de la regla, lo común será que la discusión en el ejemplo señalado se circunscriba a la aplicabilidad de dicho deber para el caso concreto. Es por ello que para Günther, "la argumentación jurídica es un caso especial del discurso moral de aplicación, en el que se trata la adecuación de la aplicación de normas". ${ }^{95}$ En donde quien argumenta jurídicamente la aplicación de una regla acepta la validez jurídica de ella y propone un paradigma de interpretación coherente del sistema jurídico, que permite la afirmación de una respuesta correcta para el caso concreto, la cual es alcanzada mediante el agotamiento óptimo del sentido normativo de las normas o principios que colisionan para el caso concreto, bajo la consideración de todas las circunstancias relevantes del caso. ${ }^{96}$ Dicha aceptación de la validez de la regla, que actúa como presupuesto de un discurso de aplicación, da cuenta correctamente del sentido que el partícipe de la práctica le atribuye a la noción de aceptación dogmática del Derecho ${ }^{97}{ }^{98}$

\footnotetext{
${ }^{93}$ GÜNTHER, "Un concepto normativo de coherencia”, cit. nota n 89, pp. 286 y ss.

${ }^{94}$ Una noción clásica al respecto es aquella formulada por Ronald Dworkin en DWORKIN, Ronald. Los derechos en serio. Ariel, Barcelona, 1984, pp. 146 y ss. La diferencia entre la noción dworkiniana de la reconstrucción del principio de coherencia y la defendida por Günther radica en que mientras la primera es de carácter monológica, recayendo en un juez que ha sido caracterizado por ello como "Hércules", la segunda se plantea dialógicamente, recayendo el deber de reconstrucción coherente del sistema jurídico para la aplicación de reglas en los participantes del discurso.

95 GÜNTHER, "Un concepto normativo de coherencia", cit. nota ${ }^{\circ}$ 89, p. 278.

${ }^{96}$ GÜNTHER, "Un concepto normativo de coherencia”, cit. nota n 89, p. 291.

${ }^{97}$ Ver supra nota 73.

${ }^{98}$ La tesis de Günther se erige como una corrección de la tesis de Alexy que describe a la argumentación jurídica como un caso especial del discurso práctico general, apoyándose en la teoría del discurso de Habermas. En términos generales, por razonamiento práctico se entiende la argumentación racional que pretende dar una respuesta correcta a preguntas prácticas, esto es, a preguntas sobre lo que se encuentra permitido, prohibido u ordenado hacer en un caso determinado. La especialidad del razonamiento jurídico vendría dado por la restricción de este razonamiento a determinadas condiciones. El razonamiento jurídico se caracteriza, en oposición al práctico general, por una restricción constitutiva de su discurso, su vinculación al derecho vigente. Los alcances y naturaleza de esta vinculación, y el grado de apertura que tiene el discurso a otro tipo de consideraciones es una cuestión debatida en la teoría de la argumentación jurídica y en la teoría general del derecho. Así, en la justificación externa de las premisas normativas radicaría el rasgo definitorio del razonamiento jurídico frente al razonamiento práctico.
} 


\section{Polít. crim. Vol. 14, No 27 (Julio 2019), Art. 16, pp. 549-598 [http://politcrim.com/wp-content/uploads/2019/06/Vol14N27A16.pdf]}

De esta forma, si bien es posible identificar distintos tipos de enunciados elaborados por teóricos del derecho, referidos a él, el discurso paradigmático lo constituye el de aplicación de reglas jurídicas, que se caracteriza por asumir la validez de las reglas a partir de la legitimidad de su forma de creación democrática, cambiando el punto de vista en el que ella es tematizada. ${ }^{99}$ Esto no impide por cierto identificar una discusión jurídica sobre la validez de una regla dentro de un sistema jurídico determinado o incluso utilizar argumentos propios de la fundamentación de la regla en términos generales para proponer la adecuación de ella a un caso de aplicación complejo, ${ }^{100}$ ni identificar enunciados descriptivos del derecho dentro de un determinado paradigma interpretativo.

Junto a la aceptación de la validez de la regla caracteriza también al discurso de aplicación, la asunción contrafáctica del ideal de un sistema coherente de reglas (la razón práctica no se contradice $)^{101}$ mediante la formulación de propuestas de integración coherente del sistema

En general, el juicio jurídico se fundamenta en dos aspectos, la justificación interna y externa. Por justificación interna se entiende la argumentación tendiente a demostrar que la decisión es una conclusión o deducción válida de las premisas esgrimidas como razones justificatorias. Mientras que por justificación externa se entiende la fundamentación de la pertinencia de las premisas justificatorias esgrimidas. (Así en ALEXY, Robert. "Teoría de la Argumentación Jurídica", Madrid, 1989, pp. 214 y ss.) Sin embargo, Habermas objeta esta concepción del razonamiento jurídico, toda vez que la tesis "sugiere una subordinación errónea del derecho a la moral". (HABERMAS, "Facticidad y Validez", cit. nota $n^{\circ}$ 87, pp. 301 y ss. Especialmente p. 305.) Para este autor, mediante su fundamentación de la racionalidad de la acción comunicativa, el principio del discurso permite, debido a su alto nivel de abstracción, una diferenciación del principio moral y democrático como especificaciones diversas del principio, referido a diversas clases de normas de acción. La diferencia que existe entre el razonamiento jurídico y el práctico no se debería a que el primero es un subconjunto del segundo, dado su peculiaridad de ser vinculantes jurídicamente, sino que se debe a que responden a consideraciones diversas. En el procedimiento democrático de creación de normas jurídicas se encuentran imbricados argumentos de diversa especie, a saber, morales, éticos y pragmáticos, lo que procedimentalmente genera una dimensión de validez de las normas jurídicas diversa a la que se puede plantear para normas morales. Sin embargo, para Alexy la tesis del razonamiento jurídico como caso especial del práctico, no tendría la implicancia de la subordinación que rechaza Habermas, sino que sólo tendría la virtud de destacar que en ambos casos nos encontramos ante procedimientos relacionados con normas, reconociendo que la naturaleza de ambas normas son distintas, dado que al incluir normas morales en el ordenamiento jurídico, éstas cambian su forma de validez. Así expresamente en ALEXY, Robert. "La tesis del caso especial", Isegoría, $\mathrm{N}^{\circ} 21, \quad$ p. $23-35$, p. 29, disponible en http://isegoria.revistas.csic.es/index.php/isegoria/article/viewFile/75/75 [visitada 22.010.2018]. En cualquier caso, lo que resulta crucial para nuestros efectos es la falta de distinción de la que adolece la tesis de Alexy entre la argumentación realizada para la fundamentación de normas, respecto de aquella realizada para la aplicación de normas, lo que resulta trascendental a la hora de evaluar la pretensión de corrección de los enunciados producidos por la dogmática jurídica.

${ }^{99}$ GÜNTHER, "Un concepto normativo de coherencia”, cit. nota n 89, p. 287.

${ }^{100}$ Esto es característico en la dogmática penal, en donde la referencia al bien jurídico protegido por las reglas de comportamiento constituye un argumento ampliamente reconocido para determinar el ámbito de aplicación de las mismas.

${ }^{101}$ Esto es equivalente al contenido heurístico que le atribuye Núñez en algún sentido a la hipótesis del legislador racional, esto es, que el ordenamiento jurídico se caracteriza por ser completo, coherente y cerrado, debiendo el dogmático desarrollar su discurso para satisfacer dichas máximas o pretensiones del sistema. Pese a que Núñez crítica dicha asunción por carecer de una meta-regla o de medios para determinar una única solución correcta. NÚÑEZ VAQUERO, "Dogmática jurídica", cit. nota $n^{\circ} 2$, pp. 251 y ss. La afirmación de Núñez le resta todo valor racional a la argumentación jurídica, estrellándose con la autocomprensión de la práctica y las pretensiones de validez que son observables en el lenguaje empleado por la dogmática para emitir sus enunciados ¿Por qué tiene sentido criticar una teoría dogmática o incluso una sentencia y sus argumentos por parte de la dogmática? Porque asumimos que existe una respuesta correcta, que podemos 


\section{SCHURMANN, Miguel “¿Es científico el discurso elaborado por la dogmática jurídica? Una defensa de la pretensión de racionalidad del discurso dogmático elaborado por la ciencia del derecho penal".}

haciendo referencia a grupos de casos que comparten características relevantes en común, de modo de entregar soluciones a problemas de aplicación de normas jurídicas. ${ }^{102}$ Dicha formulación se rige por las reglas y principios de la argumentación jurídica. De modo que la dogmática jurídica constituye una práctica argumentativa que reconoce un marco normativo de actuación que permite deslindar opiniones jurídicas gobernadas por las reglas de la práctica, de aquellas que no se ciñen a dichas reglas. ${ }^{103}$

Sin embargo, la constricción de la argumentación viene dada no solo por las disposiciones contenidas en los textos autoritativos y un determinado método, sino que también por el ideal sistemático que gobierna la interpretación de las reglas. Dado que la dogmática jurídica utiliza como heurística de sus programas, entre otros, la explicitación de los presupuestos de racionalidad implícitos en el derecho positivo ${ }^{104} \mathrm{y}$ en el lenguaje. ${ }^{105} \mathrm{La}$ comprensión de la labor dogmática como un caso especial de la argumentación moral de aplicación y la pretensión de racionalidad que lleva ínsita la argumentación jurídica, implican la asunción de una teoría metaética cognitivista de la moral. ${ }^{106}$ Este ideal de rectitud inmanente es reconocible, primariamente, como un ideal de rectitud del Derecho

discutir con razones sobre cuál es ella, y que dichos argumentos tienen una capacidad persuasiva con independencia de sus efectos perlocucionarios.

102 GÜNTHER, “Critical Remarks on Robert Alexy’s 'Special-Case Thesis”, cit. nota n’ 91, p. 155.

${ }^{103}$ Una distinción básica se encuentra entre los argumentos de lege lata, propiamente dogmáticos, y de lege ferenda, en donde se pueden agrupar tanto argumentos de técnica legislativa, como aquellos destinados a proponer una regulación alternativa, sin embargo, sobre ellos la opinión del dogmático no tiene preeminencia alguna sobre la discusión democrática. (KINDHÄUSER “Die deutsche Strafrechtsdogmatik", cit. nota n²0, pp. 963 y s.) La otra distinción se refiere a lo que se conoce como el problema de la demarcación, en donde el apego al método constituye un factor decisivo para atribuirle el carácter de teoría dogmática a aquella que emite sus enunciados bajo un ideal sistemático, esto es, aquella que proponga su integración coherente en el sistema jurídico como un todo (ver infra 4.3).

${ }^{104}$ Así, de acuerdo a Bascuñán Así, la dogmática explicita en sus proposiciones teóricas: (i) Los presupuestos metajurídicos indisponibles, entendiendo por estos las condiciones del mundo que intentan ser reguladas por el Derecho; (ii) Los presupuestos legitimatorios generales. Estos son los principios de justicia política que informen el ordenamiento jurídico desde la Constitución; y (iii) Los antecedentes históricos de la legislación. BASCUÑ̂́N RODRÍGUEZ, “Observaciones sobre la ciencia del derecho”, cit. nota n 7, p. 24. Bajo un sistema "abierto" de Derecho Penal, en los términos defendidos por Roxin y Schünemann, dicha apertura hace referencia precisamente al sentido heurístico que le es reconocido a las finalidades político-criminales legítimas en un Estado de Derecho. SCHÜNEMANN, "Introducción al pensamiento sistemático en Derecho Penal", cit. nota ${ }^{\circ} 31$, pp. 37 y ss.

${ }^{105}$ La vinculación necesaria entre el Derecho y el lenguaje no puede ser soslayada. Más allá que el uso del lenguaje -como medio ineludible de despliegue de la argumentación dogmática- permite identificar las pretensiones de validez insertas en él (ver nota infra 107), Schünemann reconoce en el lenguaje (siguiendo en esto a Wittgenstein) un marco de precomprensión y ordenamiento que permite asociar distintos objetos mediante numerosas variables. SCHÜNEMANN, "Introducción al pensamiento sistemático en Derecho Penal", cit. nota ${ }^{\circ} 31$, p. 33.

${ }^{106}$ De acuerdo a las tradicionales taxonomías de las teorías morales, las teorías cognitivistas de la moral se caracterizan por postular que existe una verdad moral accesible por medio de la razón, la cual nos otorga un estándar válido para evaluar la corrección moral de la argumentación práctica. En oposición a este tipo de teorías, las teorías no cognitivistas de la moral postulan que no es posible conocer ni discutir racionalmente asuntos morales, por ejemplo, porque estas no son más que preferencias personales de quienes las proponen. Crítico respecto de la nomenclatura (prefiriendo la distinción descriptivista y no-descriptivista) pero muy aclaratorio en cuanto a las categorías, ver HARE, R. M. “Taxonomía”, en: Ordenando la Ética. Barcelona: Ariel, 1999. pp. $49-69$, pp. 49 y ss. 


\section{Polít. crim. Vol. 14, No 27 (Julio 2019), Art. 16, pp. 549-598 [http://politcrim.com/wp-content/uploads/2019/06/Vol14N27A16.pdf]}

vigente, que el dogmático tiene la tarea de descubrir, y desarrollar heurísticamente en sus discursos elaborados sobre la legislación y, secundariamente, en la corrección o rectitud implícita en la postulación de la adecuación de la regla en un discurso (moral o jurídico) de aplicación.

Así, la pretensión de corrección de la fundamentación de las reglas que son parte de un sistema jurídico tiene un significado distinto a la pretensión de corrección que se encuentra inserta en un enunciado que sostiene la aplicabilidad de la regla para un caso concreto. Sin embargo, ambas pretensiones de corrección se caracterizan por aspirar a ser racionales y poder ser desempeñadas discursivamente en términos equivalentes, ${ }^{107}$ dado que constituyen pretensiones de validez que pueden ser identificadas en el lenguaje de los partícipes de la práctica dogmática, cuya identificación, por cierto, solo es posible si se asume la posición teórica del partícipe para describir la práctica. ${ }^{108}$ Dichas pretensiones de validez insertas en el lenguaje empleado al formular teorías dogmáticas se ve reflejado en tanto ellos proponen soluciones interpretativas de la legislación para potenciales problemas del discurso de aplicación de reglas jurídicas, asumiendo una carga de argumentación recíproca que se desempeña mediante la crítica de los enunciados y la aportación de razones en pro y en

${ }^{107}$ La noción de desempeño discursivo de pretensión de corrección -tanto para la teoría de Günther como de Alexy- es dependiente de la teoría de la acción comunicativa en los términos formulados por Jürgen Habermas. La teoría de este autor se basa en la noción de acción comunicativa, como acción orientada al entendimiento. Este tipo de acción es caracterizada por que los participantes coordinan de común acuerdo sus planes de acción. Este consenso se consigue por el reconocimiento intersubjetivo de las pretensiones de validez. En este sentido, el hablante aduce afirmaciones con pretensiones de validez de distinto tipo, ya sea de inteligibilidad, verdad, rectitud o veracidad, bajo la garantía de que puede dar razones que justifiquen su afirmación. En esta teoría las pretensiones de validez se fundamentan en el reconocimiento que es posible de realizar en el uso del lenguaje corriente. Todos planteamos enunciados con pretensiones de validez intersubjetiva, es decir, pretendemos el entendimiento y reconocimiento de otros. La única forma de identificar pretensiones en el lenguaje es adoptar la perspectiva del partícipe en la descripción de la sociedad. La fundamentación de la racionalidad de los enunciados morales, por ejemplo, se basa en una teoría global de las pretensiones de validez que se encuentran ínsitas en el lenguaje. Todo planteamiento de pretensiones de validez puede ser controvertida mediante la exigencia del uso de la garantía de razonabilidad. El uso de la garantía obliga a los participantes al uso de los argumentos, los cuales son evaluados en su racionalidad mediante el uso del principio de la 'universalidad', en una formulación dialógica que supera la noción kantiana del principio y funciona como puente que permite el entendimiento en las discusiones morales. La superación de la versión kantiana del principio viene dado por dejar de entender la fundamentación como un acto de un solo individuo que plantea normas para la universalidad, para pasar a un discurso en que todos los participantes contribuyen a la creación de la norma universal. HABERMAS, Jürgen. "Ética del discurso. Un programa de fundamentación”, en: GARCÍA COTALERO, Ramón (Traductor), Conciencia moral y acción comunicativa, Barcelona: Península, 1983. pp. 59-134.

${ }^{108}$ La postura del partícipe (ver supra nota 72 ) se caracteriza por el reconocimiento de diversas dimensiones del uso del lenguaje, de acuerdo a la teoría de pragmática universal. De acuerdo a dicha teoría, son dimensiones de los actos de habla las siguientes: (i) Locucionario: Es el sentido lógico que pretende la inteligibilidad del acto; (ii) Ilocucionario: Es la dimensión del sentido y contexto del acto; (iii) Perlocucionario: Esta es la dimensión que permite dar cuenta de los efectos del acto. La dimensión ilocucionaria se genera en un tipo de relación interpersonal que se caracteriza por los vínculos intersubjetivos. Estos vínculos son producto del reconocimiento de las pretensiones de validez propias del lenguaje. A la aproximación metodológica del partícipe, se opone la postura que se sitúa en la posición de observador, la que se caracteriza, por su parte, en la dilución de la dimensión ilocucionaria del lenguaje en la dimensión perlocucionaria del mismo. Es decir, para esta postura metodológica, la descripción de una comunicación social, como la argumentación moral o la postulación de una teoría dogmática, puede ser descrita verosímilmente sólo mediante la constatación de los efectos que el lenguaje produce en la sociedad. 


\section{SCHURMANN, Miguel “¿Es científico el discurso elaborado por la dogmática jurídica? Una defensa de la pretensión de racionalidad del discurso dogmático elaborado por la ciencia del derecho penal".}

contra de una determinada propuesta interpretativa, pretendiendo el reconocimiento de la comunidad no solo como enunciados racionales sino como la propuesta interpretativa correcta, en virtud de la motivación que entrega el desempeño del mejor argumento en condiciones ideales. Las condiciones de desempeño de la garantía argumentativa de la dogmática carecen de las restricciones temporales y de conocimiento propios de la actividad realizada por la judicatura, sobre la cual pesa el principio de inexcusabilidad, pudiendo renovar indefinidamente discusiones dogmáticas en busca de un progreso en la comprensión de la regulación legal. Con ello, la pretensión de racionalidad de los enunciados prescriptivos de la dogmática jurídica pueden ser desempeñados de modo equivalente a los enunciados constatativos ${ }^{109}$ propios de las ciencias empíricas, los cuales también son discutidos en base a razones.

Con ello, para todo discurso reflexivo de aplicación, estructurado como teoría dogmática, junto al requerimiento de coherencia interpretativa del sistema de normas jurídicas pertenecientes al caso, propio de todo discurso de aplicación, constituirán también baremos para evaluar la corrección de una teoría dogmática tanto su fuerza aclaratoria, como la ausencia de contradicciones valorativas y sistemáticas entre sus presupuestos y aplicaciones pretendidas, el respeto al sentido literal posible de una disposición y la utilización de la metodología jurídica regente. Por cierto, una postura racionalista sobre la discusión dogmática, que asuma el ideal de corrección del sistema y una reducción de su indeterminación del Derecho de modo de asegurar una sola respuesta correcta (aunque solo se sostenga como aquí en un sentido procedimental y no de contenido), ${ }^{110}$ se ubica en las antípodas teóricas del escéptico radical que describe la discusión dogmática utilizando como analogía, por ejemplo, la labor del cocinero, ${ }^{111}$ dado que no existiría garantía alguna de que la solución propuesta por la dogmática sea la correcta, sino que dependería más de las preferencias subjetivas de quien la reconoce como útil o idónea para sostener su punto de vista. ${ }^{112}$ Efectivamente la garantía de racionalidad, cuando se ha abandonado una noción

\footnotetext{
${ }^{109}$ La teoría de Habermas distingue entre diversas pretensiones de validez en el uso corriente del lenguaje, a saber, inteligibilidad, verdad, rectitud y veracidad. Así lo que caracteriza a los enunciados constatativos, particularmente relevante para las teorías científicas, es la pretensión de verdad que se postula al enunciarlos. En el caso de los enunciados morales, estos se caracterizan por la pretensión de corrección o rectitud que plantean. Sin embargo, si bien ambos enunciados se plantean, sostienen o desechan en el ámbito dado por la lógica del discurso, tienen 'asimetrías', dado que coordinan la acción de forma distinta y en referencia a objetos lingüísticos diversos.

${ }^{110}$ GÜNTHER, “Critical Remarks on Robert Alexy's 'Special-Case Thesis", cit. nota n ${ }^{\circ}$ 91, pp. 151 y s.

111 "Existen, en este sentido, al menos dos importantes diferencias entre las disciplinas técnicas (o tecnológicas) como la aeronáutica o la medicina y la dogmática jurídica interpretativa. La primera de ellas consiste en que, mientras que nadie pone en cuestión cuándo una propuesta técnica tiene éxito - cuando el avión vuela o cuando la persona se cura - porque disponemos de criterios compartidos para determinar el éxito en tales disciplinas, ocurre precisamente lo contrario cuando hablamos de la dogmática jurídica. ¿Cuándo estamos frente a una buena construcción dogmática? ¿Cuando resulta persuasiva? ¿Cuando alcanza la respuesta correcta? ¿Cuando está bien justificada? En tal sentido, la dogmática se parece más a la cocina que a la medicina, puesto que el éxito de una propuesta dogmática no depende de criterios objetivos sino de preferencias subjetivas". NÚÑEZ VAQUERO, "Sobre 'algunos argumentos", cit. nota n 63, p. 510, nota 17.

112 "Si no podemos garantizar que las respuestas provenientes de la dogmática jurídica sean mejores respuestas desde el punto de su contenido moral o ético político: ¿para qué queremos una dogmática que oriente, mediante juicios ético-políticos, las decisiones de los jueces?" NÚÑEZ VAQUERO, "Sobre 'algunos argumentos", cit. nota $\mathrm{n}^{\circ} 63$, p. 522.
} 


\section{Polít. crim. Vol. 14, № 27 (Julio 2019), Art. 16, pp. 549-598 [http://politcrim.com/wp-content/uploads/2019/06/Vol14N27A16.pdf]}

de derecho natural, ya no puede ser de contenido sino que procedimental. Dicha garantía procedimental se encuentra vinculada para un discurso de fundamentación en la legitimidad y validez jurídica del sistema democrático de creación de reglas, mientras que para un discurso de aplicación radica en el deber de una descripción completa del caso y una coherente interpretación de todas las normas válidas directa o indirectamente aplicables al mismo, sustentado ello por argumentos que deben ser entregadas en el evento que la pretensión de racionalidad no sea simplemente aceptada. Si bien esto no entregará mecánicamente una solución, sí entregará el marco para analizar y eventualmente impugnar discursivamente la racionalidad de las proposiciones teóricas de aplicación de reglas, ${ }^{113}$ lo cual describe de mejor manera lo que los propios dogmáticos entienden que realizan al discutir académicamente, ${ }^{114}$ en donde se discute asumiendo por los partícipes que sólo existe una respuesta interpretativa correcta, la que debe ser construida mediante argumentación racional.

Con ello, tenemos una relación de equivalencia o conmensurabilidad tanto en la conformación de presupuestos teóricos y metodológicos de paradigmas científicos y dogmáticos, como en el nivel de la forma de desempeñar críticamente las pretensiones de validez enunciados por ambos tipos de discurso teórico. ${ }^{115}$ Más allá de la diferente conexión que se presenta entre un enunciado constatativo y la realidad, en donde la validez de una teoría científica cuyas aplicaciones pretendidas se desempeñan en afirmaciones predictivas que pueden ser contrastadas con la realidad bajo una teoría de la verdad como correspondencia, ${ }^{116}$ o cuyo contraste con la realidad ofrece razones de diverso tipo para una teoría discursiva o consensual de la verdad, la vigencia u obsolescencia de dicha teoría como medio idóneo para describir determinado segmento de la realidad será discutido discursivamente.

La compatibilidad de las descripciones teóricas de las funciones de las teorías dogmáticas aquí formuladas con aquellas descritas como autocomprensión de la dogmática jurídico penal en supra 2.2. es evidente. Los enunciados teóricos realizados por la dogmática jurídica, ya sean descriptivos o prescriptivos, para la reconstrucción racional del derecho vigente en orden a prever la solución interpretativa correcta para potenciales casos, bajo las

\footnotetext{
${ }^{113}$ GÜNTHER, “Critical Remarks on Robert Alexy's 'Special-Case Thesis”, cit. nota no 91, p. 151 y ss.

${ }^{114} \mathrm{Y}$ no meramente compartir recetas interpretativas para que cualquier consumidor elija la de su preferencia, tal como da entender la metáfora del cocinero. Es difícil pensar en alguna comprensión de las reglas establecen los deberes de fundamentación de las sentencias que pueda ser asumida como correcta por parte de los partícipes del discurso jurídico, que se satisfaga con la mera narración de las motivaciones y preferencias subjetivas del aplicador del derecho. Más allá de que pueda existir un grado de indeterminación sobre cómo se encuentra conformado el parámetro de racionalidad que le es exigible a la judicatura, el sistema reconoce su existencia, al prever recursos para impugnar su déficit. En este sentido, como correctamente identifica Wittgenstein, lo que necesitamos a este respecto no es una definición de dicho parámetro, sino que una explicación de él que permita aplicarlo adecuadamente, y así delimitar cuándo una propuesta argumentativa de aplicación lo satisface. WITTGENSTEIN, Philosophische Untersuchungen. cit. nota n 72, pp. 144 y ss.

${ }^{115}$ Realiza una comparación cercana PEÑA GONZÁLEZ, Carlos. "El Valor Científico del Derecho", Revista Derecho y Humanidades, pp. 31 - 38. Santiago, Chile. Número 6 (1998), pp. 36 y ss. Disponible en: https://revistas.uchile.cl/index.php/RDH/article/view/25781/27109 [visitado 22.03.2018].

${ }^{116}$ Por cierto una eventual adhesión a una determinada teoría de la verdad excede el objeto de este trabajo. Una interesante defensa de una teoría de la verdad como correspondencia se encuentra en SEARLE, John. La construcción de la realidad social, Paidos, 1997, Capítulos 7 a 9.
} 


\section{SCHURMANN, Miguel “¿Es científico el discurso elaborado por la dogmática jurídica? \\ Una defensa de la pretensión de racionalidad del discurso dogmático elaborado por la ciencia del derecho penal".}

condiciones teóricas de un discurso de aplicación, pretenden ser reconocidos como racionales por los partícipes de la práctica y se desempeñan por medio de razones. Ellos responden a un paradigma epistemológico en los términos descritos precedentemente y que difiere tanto de la metodología como del tipo de conocimiento predictivo propio de las ciencias empíricas y lógicas. ${ }^{117}$ Las preguntas que deben ser formuladas ahora son aquellas que ocuparon a la filosofía de las ciencias, a saber: (i) cómo podemos demarcar qué cuenta como teoría dogmática, en oposición a aquella que no alcanza dicho estándar y puede ser calificada como topoi, y (ii) si es racional el cambio teórico, en los términos propuestos por Lakatos -y en oposición a Kuhn- en el ámbito de la filosofía de las ciencias.

\subsection{La conformación y estructura de las teorías como programas de investigación dogmáticos}

La valoración de la racionalidad del discurso dogmático debe partir necesariamente del estadio reflexivo actual sobre el rol de la racionalidad tanto en los términos desarrollados por la filosofía de las ciencias, como en los términos de racionalidad crítica desarrollados por la hermenéutica para las ciencias sociales. El conocimiento de las ciencias del espíritu puede plantearse como "una empresa crítica que apunta a dilucidar resultados y métodos de las disciplinas individuales, y a someterlos a la luz de determinados ideales de conocimiento y programas de investigación". ${ }^{118}$ Definidas las características sobresalientes y pretensiones de la dogmática, así como el sentido en que su discurso puede postular para ser catalogado como racional, se debe precisar lo que se entiende como teoría dogmática, es decir, se debe definir qué tipo de conjunto de enunciados o modelo puede ser catalogado como teoría dogmática. Tal como fue analizado en supra 3, la discusión ha ido avanzando en el sentido de comprender a las teorías científicas como comprehensivas de bastantes más contenidos que meros enunciados proposicionales de naturaleza empírica, debiendo contemplar en ella también sus presupuestos teóricos y metodológicos, y en las cuales las aplicaciones pretendidas son incluidas también dentro de aquello que puede ser falseado.

De forma previa a evaluar la racionalidad de disputas dogmáticos se debe tomar partido por el denominado problema de la demarcación. ¿Qué cuenta como una teoría dogmática? Para buscar una respuesta a esta pregunta, Canaris asume que la moderna metodología de las ciencias, en especial el estructuralismo, es enteramente aplicable a la función y práctica de las teorías dogmáticas. Esto se debe principalmente al giro que desarrolló esta teoría en el ámbito metodológico al comprender a las aplicaciones pretendidas como parte integrante de la teoría. Desde esta perspectiva, Canaris propone calificar como teoría dogmática a una solución práctica a la luz de un caso paradigmático expandible por analogía, enlazados sistemáticamente. ${ }^{119}$ La primera virtud de la definición de Canaris es vincular la actividad dogmática a la labor propia del discurso de aplicación de reglas. Pese a que la crítica del derecho vigente e incluso la propuesta de reformas legislativas pueden ser actividades desarrolladas por los juristas, no por ello dichos enunciados pueden ser agrupados y

\footnotetext{
${ }^{117} \mathrm{El}$ análisis de una ciencia jurídica entendida en dichos términos es realizado en infra 5.1.

${ }^{118}$ ALBERT, Hans. Conocimiento y derecho. La jurisprudencia a la luz del criticismo, Barcelona: Paidos, 2002 , p. 110.

${ }^{119}$ CANARIS, Función, estructura y falsación de las teorías jurídicas, cit. nota no 12 , p. 41.
} 


\section{Polít. crim. Vol. 14, No 27 (Julio 2019), Art. 16, pp. 549-598 [http://politcrim.com/wp-content/uploads/2019/06/Vol14N27A16.pdf]}

definidos como una teoría dogmática. El desempeño de las funciones atribuidas a la dogmática constituye así el criterio para delimitar a las teorías de otras actividades. Sin embargo, la realización de las funciones no constituye el estándar mínimo de reconocimiento de una teoría dogmática.

El requisito de enlazamiento sistemático, propuesto por Canaris, pretende dar cuenta del sentido que le atribuye, por ejemplo, la dogmática penal a lo que se denomina como teoría general del delito o del hecho punible, cuya tradición teórica, como teoría de la imputación, se remonta con claridad hasta la filosofía práctica del siglo XVII ${ }^{120}$ y que ha sido desarrollada de forma paralela y con relativa independencia de las leyes vigentes. Bajo dicha comprensión sistemática del derecho penal, constituye un requisito ineludible de toda propuesta interpretativa de las reglas de la parte general del derecho penal su enlazamiento o vinculación con una determinada teoría del delito o con una determinada precomprensión de la ordenación sistemática de los elementos del injusto penal que ella supone. Sin ello, la propuesta interpretativa no satisface los requisitos mínimos de una teoría dogmática, dado que no garantiza que ella no responda a un mero decisionismo espontáneo o singular. Este requisito de enlazamiento sistemático reafirma al mismo tiempo la pretensión de racionalidad interna del Derecho. ${ }^{121}$ Por cierto dicho enlazamiento sistemático no asume como presupuesto teórico la posibilidad de una ordenación axiomática del sistema jurídico, cuyo contenido heurístico permita ser deductivamente derivado por parte de la dogmática a partir de principios fundantes, ${ }^{122}$ sino que, al contrario, la posibilidad constructiva de elaborar una teoría coordinada y articulada, en la medida que la dogmática trabaje bajo métodos generalmente reconocidos y cuyas propuestas sean críticamente evaluadas. ${ }^{123}$ En esta medida, la sistematización o el trabajo sistemático que realiza la dogmática penal responde a los requerimientos formulados por Günther para el trabajo dogmático, en tanto el tratamiento de grupos de casos responden a propuestas interpretativas del derecho

\footnotetext{
${ }^{120}$ HRUSCHKA, Joachim. “¿Puede y debería ser sistemática la dogmática jurídico-penal?”, en: SÁNCHEZOSTIZ, Pablo (edit.), Imputación y Derecho Penal, Editorial BdeF, 2009, pp. 333 - 368, pp. 361 y ss. De forma más comprehensiva en HRUSCHKA, Joachim. "Zurechnung seit Pufendorf. Insbesondere die Unterscheidungen des 18. Jahrhunderts", en: KAUFMANN / RENZIKOWSKI (editores), Zurechnung als Operationalisierung von Verantwortung, 2004, pp. 17-27.

${ }^{121}$ VEGA "Las calificaciones del saber jurídico", cit. nota n 4, p. 395; KINDHÄUSER "Die deutsche Strafrechtsdogmatik", cit. nota ${ }^{\circ}$ 20, p. 954; HRUSCHKA, "Puede y debería ser sistemática la dogmática jurídico-penal?", cit. nota n 120, p. 358.

${ }^{122}$ Conforme con un ideal de coherencia vinculado al método, en oposición a una deductibilidad a través de axiomas. SCHÜNEMANN, "Introducción al pensamiento sistemático en Derecho Penal", cit. nota n 31, p. 73.

${ }^{123}$ Hruschka da cuenta de los dos sentidos en que la expresión "sistemático" puede ser utilizado cuando se hace referencia a un determinado ámbito de investigación. "En el primer sentido de la expresión, una investigación es sistemática cuando desemboca en una teoría coordinada, articulada y -habría que añadir comprensiva [umfassende]. En el segundo sentido, una investigación es sistemática si procede de acuerdo con los métodos generalmente reconocidos y sus resultados son medidos según los criterios generalmente reconocidos". HRUSCHKA, "Puede y debería ser sistemática la dogmática jurídico-penal?", cit. nota n 120 , p. 333. Aquí es utilizada en el segundo sentido, en el mismo que el propio Hruschka cree posible el trabajo de la dogmática jurídica, dado que no cree posible articular axiomáticamente una teoría comprensiva del hecho punible a partir de fundamentos de teoría de la pena (p. 341). Sin embargo, es precisamente el trabajo de la dogmática en el segundo sentido el que arrojaría como resultado la construcción de una teoría del hecho punible comprensiva, articulada y libre de contradicciones, invirtiendo el proceso de generación de una teoría axiomática, desde uno de naturaleza deductivo hacia uno constructivo (p. 359).
} 


\section{SCHURMANN, Miguel “¿Es científico el discurso elaborado por la dogmática jurídica? Una defensa de la pretensión de racionalidad del discurso dogmático elaborado por la ciencia del derecho penal".}

vigente que asumen como requisito la carga argumentativa presupuesta por el ideal de coherencia previsto para todo discurso de aplicación de regla.

Sin embargo, si bien el enlazamiento sistemático podría dar cuenta del requisito de vinculación libre de contradicción lógica y valorativa de la solución interpretativa propuesta de la legislación por parte de una teoría dogmática, ${ }^{124}$ realizando con ello el ideal de coherencia implicado en ella, la conexión propuesta parece ser descriptivamente insuficiente. El estándar propuesto por Canaris para considerar propuestas interpretativas del derecho vigente como teorías dogmáticas es muy modesto, ya que permite aceptar como teorías dogmáticas a propuestas interpretativas sin la densidad teórica con la que son comprendidas por los partícipes de la práctica, pudiendo confundir una aplicación de una teoría mayor con una solución interpretativa autónoma. Así, bajo el estándar de Canaris, por ejemplo, sería posible distinguir como dos teorías independientes -aunque enlazadas sistémicamente- una teoría sobre el fundamento penal de la tentativa respecto de una teoría que delimite la punibilidad de la tentativa frente a hipótesis de inidoneidad o respecto de actos preparatorios. Al contrario, cuando se sostiene que la respuesta teórica a dichos problemas responde a un único programa teórico, el falseamiento o impugnación por incorrección de una de las aplicaciones pretendidas de la teoría puede contar como una instancia de falsación íntegra de un programa de investigación que acumula de esa forma déficit explicativos. Así, constituiría un déficit explicativo para una teoría que intente dar cuenta del fundamento de la sanción de la tentativa una descripción inverosímil del tratamiento que el derecho vigente realiza de lo que teoría califica como tentativa inidónea, cuya consecuencia jurídica propuesta es la impunidad por falta de subsunción en la regla respectiva. Es por ello que el estándar debe ser necesariamente más exigente, toda vez que debe considerarse como teorías dogmáticas a un grupo de enunciados teóricos relacionadas sistemáticamente, cuyo complejo realice o satisfaga por si mismo el ideal de coherencia propio del discurso de aplicación de reglas.

Así, una teoría dogmática sometida a la garantía de racionalidad propia del discurso de aplicación debe ofrecer soluciones interpretativas no solo respecto de determinadas disposiciones legales, sino que debe ser capaz de argumentar suficientemente también que dicha interpretación constituye una comprensión coherente en relación a las instituciones y categorías jurídicas del resto del sistema jurídico, de modo que la consistencia y unidad del sistema sean garantizados argumentativamente, cumpliendo de esa forma con las funciones que le son asignadas a la dogmática para la racionalización del derecho vigente. ${ }^{125}$ Esto

\footnotetext{
${ }^{124}$ A modo de ejemplo, puede señalarse que la falta de contradicción es erigida como criterio fundamental por Schünemann para descartar el carácter científico del sistema jurídico penal francés "Esto afecta, en primer lugar, al sistema penal francés, el cual, a través de la alineación brusca, desde el punto de vista lógico, de «elementos» dispares, no cumple con los requisitos básicos de la formación científica de un sistema, a saber: la economía de conceptos y la ausencia de contradicciones". SCHÜNEMANN, Bernd. "El propio sistema de la teoría del delito", Indret, $\mathrm{N}^{\circ}$ 1, 2008, pp. 1 - 20, p. 5. Disponible en: http://www.indret.com/pdf/505.pdf [visitado 22.03.2018].

${ }^{125}$ Demostraciones de la fecundidad del trabajo sistemático para la reconstrucción racional del derecho vigente son ejemplificados en HRUSCHKA, "Puede y debería ser sistemática la dogmática jurídico-penal?", cit. nota $\mathrm{n}^{\circ} 120$, pp. 346 y ss. Al contrario, la incompatibilidad de una determinada propuesta interpretativa
} 


\section{Polít. crim. Vol. 14, № 27 (Julio 2019), Art. 16, pp. 549-598 [http://politcrim.com/wp-content/uploads/2019/06/Vol14N27A16.pdf]}

permite considerar teorías dogmáticas a las grandes teorías, en tanto constituyen asociaciones reticulares que se extienden por todo el subsistema jurídico para el supuesto de aplicación racional del derecho vigente para sistemas de casos, incluyendo dentro del análisis no solo dichos contextos de aplicación, sino que también los presupuestos teóricos y metodológicos (también denominados "puntos de partida teóricos") en tanto son ellos los que permiten integrar el sistema, proponiendo no solo una precomprensión de las categorías integrantes del sistema jurídico, sino que entregando también los puntos de apoyo necesarios para el desarrollo futuro de la dogmática. ${ }^{126}$ De modo que, tal como da cuenta Kuhn para el estado de ciencia normal o Lakatos para la ciencia madura, lo habitual es apreciar en las aportaciones que son realizadas al discurso - de acuerdo a la comprensión de los partícipes- constituyen la aplicación del contenido heurístico de paradigmas generales y no la creación de una teoría dogmática propiamente tal. ${ }^{127} \mathrm{La}$ elección del parámetro de demarcación precedente, para los efectos de este análisis, tampoco es causal, facilita la conmensurabilidad de las teorías dogmáticas con los programas de investigación científicos bajo la modalidad postulada por Lakatos.

Si bien esto exige un mínimo de densidad teórica para los efectos de calificar enunciados dogmáticos como una teoría, es importante clarificar que dicho estándar no debe ser satisfecho por cada aportación teórica singular realizada por el dogmático, sino que, en tanto práctica cultural colectiva, una propuesta interpretativa puede exhibir su vinculación teórica o sistemática mediante la referencia ${ }^{128}$ a los programas de investigación reconocidos

respecto de otras instituciones o normas no previstas como situaciones de aplicación suele ser argumentado como instancia de falsación en discusiones dogmáticas.

${ }^{126} \mathrm{La}$ reflexión sobre los presupuestos teóricos y metodológicos de los paradigmas interpretativos en el ámbito del derecho penal es recurrente. Una exposición y análisis de los presupuestos teóricos y metodológicos de los sucesivos programas de investigación dogmático dominantes en el Derecho penal alemán se encuentra en SCHÜNEMANN, "Introducción al pensamiento sistemático en Derecho Penal”, cit. nota $\mathrm{n}^{\circ} 31$, pp. 43 y ss. Un análisis de los presupuestos teóricos y metodológicos de los programas de investigación dogmáticos funcionalistas, en los términos propuestos por Roxin y Jakobs se encuentra también en SCHURMANN OPAZO, Miguel Antonio, Dogmática jurídica y racionalidad científica: análisis de los presupuestos epistémicos de las teorías dogmáticas a la luz del debate sobre la sanción de la tentativa inidónea en el derecho penal alemán. Memoria de Prueba para optar al grado de Licenciado en Ciencias Jurídicas y Sociales. Profesor guía: Antonio Bascuñán Rodríguez. Universidad de Chile. 2007. Capítulos III.1-4 para Roxin y IV.1-5 para Jakobs.

${ }^{127}$ Schünemann, por ejemplo, califica a los trabajos que suceden a su contribución en una compilación, no como la aportación de nuevas teorías del derecho penal hasta los detalles, sino que la demostración "de lo extraordinariamente fructífera y dinámica" que resulta el programa de investigación dogmático de renormativización del pensamiento de la ciencia del derecho penal. SCHÜNEMANN, "Introducción al pensamiento sistemático en Derecho Penal", cit. nota ${ }^{\circ} 31$, p. 80.

${ }^{128}$ Así, la pregunta formulada por Matus -¿Por qué citamos a los alemanes?-, admite una nueva respuesta a las ya formuladas por van Weezel y referidas a la pertinencia teórica de sus aportes para nuestros análisis (VAN WEEZEL, “¿Por qué no citamos más (por ejemplo, a los alemanes)? Réplica a J. P. Matus”, cit. nota $n^{\circ} 32$, pp. 1 y ss.). Esto es, porque reconocemos en las teorías formuladas por autores alemanes programas de investigación dogmáticos que tienen algún grado de vigencia teórica en nuestro medio cultural. Es por ello que al formular propuestas interpretativas vinculamos nuestras teorías locales a ellas, especialmente para la comprensión de la parte general del derecho penal. Por cierto, la honestidad intelectual (motivo que también reconoce van Weezel) y la objetividad en sentido popperiano, justifican y al mismo tiempo explican más adecuadamente la referencia a dichos autores que la -denunciada por Matus- búsqueda de argumentos de autoridad. MATUS ACUÑA, "Por qué citamos a los alemanes", cit. nota n 8, pp. 332 y ss. 


\section{SCHURMANN, Miguel “¿Es científico el discurso elaborado por la dogmática jurídica? Una defensa de la pretensión de racionalidad del discurso dogmático elaborado por la ciencia del derecho penal".}

dentro de la práctica dogmática, ${ }^{129}$ descargando parcialmente su deber de fundamentación teórica general, y concentrando su atención en un problema interpretativo propio de las aplicaciones pretendidas de un programa de investigación. De esta forma, cada aportación teórica no debe ser una teoría dogmática en si misma, sino que solamente una parte integrante de la misma, siendo común apreciar en la práctica la impugnación y defensa colectiva de programas teóricos, como de hecho se observa en la crítica y defensa por distintos autores de determinadas formas de programas de investigación dogmáticos funcionalistas o de determinadas comprensión de teorías de las normas. ${ }^{130}$

Con ello, la discusión teórica se presenta como el desempeño de la pretensión de racionalidad $^{131}$ de los programas de investigación dogmáticos en un multinivel. ${ }^{132}$ Esto es, tanto a nivel de fundamentos de programas de investigación y su poder heurístico, y por ello en un nivel de abstracción mayor, así como en el nivel de aplicaciones pretendidas, relacionándose también directamente con la interpretación del derecho vigente, siendo ambas instancias idóneas o susceptibles de falsación para los programas de investigación dogmáticos. ${ }^{133} \mathrm{Al}$ mismo tiempo, una descripción específica y demarcatoria de la actividad

${ }^{129}$ KINDHÄUSER “Die deutsche Strafrechtsdogmatik”, cit. nota n² 20, pp. 954 y 959 y ss. Crítico sin embargo sobre la pertinencia de la cita tanto de autores pertenecientes a tradiciones jurídicas extranjeras como de la filosofía en general, ver VERGARA BLANCO, "Teoría del Derecho, Filosofía del Derecho y Doctrina Jurídica", cit. nota $\mathrm{n}^{\circ} 3$, p. 655. Abierta y correctamente en contra de este escepticismo metodológico ver HRUSCHKA, “¿Puede y debería ser sistemática la dogmática jurídico-penal?”, cit. nota n 120, pp. 354 y ss. aludiendo a las reglas de la lógica, argumentativas, etc.

${ }^{130}$ Los ejemplos en este sentido son abundantes en múltiples sentidos. De modo ilustrativo puede identificarse la discusión sostenida tanto entre los programas funcionalistas (ver WILENMANN VON BERNATH, "Conocimientos especiales", cit. nota ${ }^{\circ}$ 69, pp. 135 y ss.) como en contra de ellos (ver nota 168), respecto de la pertinencia de la consideración de los conocimientos especiales del autor en la teoría de la imputación objetiva. Si bien la discusión teórica puede ser descrita como aquella llevada adelante por los principales sostenedores de los programas dogmáticos en disputa, Roxin y Jakobs, es frecuente la concurrencia a la discusión por parte de autores que trabajan bajo el mismo paradigma teórico. Un ejemplo se encuentra en GRECO, Luis. Das Subjektive an der objektiven Zurechnung: Zum ,Problem' des Sonderwissens. ZStW 117 (2005), pp. 519 - 554, pp. 519 ss.

${ }^{131}$ Conforme con el desempeño crítico de la pretensión de racionalidad de las soluciones propuestas por la dogmática jurídico-penal, en oposición a quienes en las propuestas dogmáticas solo observan opiniones que pueden ser contadas, ver HRUSCHKA, “Puede y debería ser sistemática la dogmática jurídico-penal?”, cit. nota $\mathrm{n}^{\circ} 138$, p. 356 y ss., 367 y s.

${ }^{132}$ En este sentido, y en contra de lo propuesto por Canaris, Schünemann da cuenta que la discusión realizada por la comunidad dogmática rápidamente se centró en la categoría de la responsabilidad, una vez que el paradigma funcionalista de Roxin comenzó a ser discutido. Con ello se demuestra que la dogmática entiende como una instancia de falsación suficiente de paradigmas dogmáticos el demostrar la inadecuación de su propuesta aclaratoria para sus aplicaciones pretendidas, dado que la crítica a la novedosa comprensión de Roxin respecto de la tradicional categoría de la culpabilidad, cuenta como una instancia de falsación de su paradigma funcionalista. SCHÜNEMANN, "Introducción al pensamiento sistemático en Derecho Penal", cit. nota $\mathrm{n}^{\circ} 31$, pp. 65 y ss.

${ }^{133}$ Una comprensión de las teorías dogmáticas en los términos descritos precedentemente es criticado por Matus al afirmar el carácter arbitrario de la elección de los "puntos de partida". MATUS ACUÑA, "Por qué citamos a los alemanes", cit. nota $n^{\circ} 8$, pp. 324 y ss. Sin embargo, la crítica, tal como se pudo apreciar en la evolución de la discusión sobre los presupuestos teóricos de los programas de investigación científico en supra 3.1., hierra en el punto. Los puntos de partida de los programas de investigación, sean científicos o dogmáticos son susceptibles de ser sometidos a una crítica discursiva en los términos planteados en supra 3.2. 


\section{Polít. crim. Vol. 14, № 27 (Julio 2019), Art. 16, pp. 549-598 [http://politcrim.com/wp-content/uploads/2019/06/Vol14N27A16.pdf]}

del jurista que puede ser descrita como formulación de una teoría dogmática, en los términos formulados, tiene el mérito de entregar un criterio para delimitar dicha actividad de otras que contingentemente puede ser realizado también por el jurista, como lo sería una propuesta legislativa, así como de otro tipo de discurso que tiene por objeto al fenómeno jurídico desde otro enfoque metodológico, como podría predicarse de la sociología jurídica o la antropología jurídica. ${ }^{134}$

\section{La pretensión de cientificidad del discurso dogmático. ¿Qué es lo que se pretende en términos rigurosos?}

Una vez descrito el tipo de discurso elaborado por la dogmática jurídica y hecha una comparación de dicha práctica con la comprensión desarrollada por la filosofía de las ciencias respecto del discurso científico, es posible regresar a la pregunta inicial sobre el carácter científico de la dogmática jurídica. La respuesta a esta pregunta admite una infinidad de puntos de vista. Por ejemplo, Núñez ${ }^{135}$ da cuenta de distintos modelos de ciencia jurídica en sentido amplio y aboga por determinar el objetivo de la práctica, esto es, el conocimiento que desea ser adquirido, antes de elegir un determinado modelo de ciencia jurídica que sea propuesto como correcto a desempeñar. Otra vía para abordar el problema es aquella elegida por Atienza, ${ }^{136}$ quien bajo la intención de realizar una descripción verosímil y autosuficiente de la práctica dogmática procura evita establecer parámetros de conmensurabilidad de tradiciones de pensamiento, optando por denominar a la dogmática como "tecno-praxis", como si el asunto se agotara con la correcta denominación epistemológica de la actividad y no se requiriere dar cuenta de la forma específica en que la racionalidad de la dogmática jurídica debe ser reconstruida y desempeñada. ${ }^{137}$

Como se pudo apreciar al revisar la autocomprensión de la dogmática penal, cuando se formula la pregunta por el carácter científico de la dogmática jurídica habitualmente se hace referencia a los dos problemas más relevantes de los que se ha hecho cargo la filosofía de las ciencias en el ámbito de las ciencias empíricas: (i) las condiciones de validez del

El hecho de que los puntos de partida sean elegidos, no los constituyen en arbitrarios ni menos en irracionales, en la medida que estén sometidos a la crítica de la comunidad científica/dogmática.

${ }^{134}$ Por ello debe rechazarse la descripción del objeto de la ciencia jurídica en términos difusos o indiferenciados. Por ejemplo, en los términos descritos por Celis tanto en un sentido amplio, como el "fenómeno jurídico"; así como en un sentido restringido, en donde describe a la dogmática jurídica indiferenciadamente como "la Ciencia sobre el Derecho positivo, esto es, sobre el ordenamiento jurídico considerado como presupuesto dogmático de estudio. Se trata de una rama pura u originaria de la Ciencia Jurídica que se aboca al estudio inmanente del Derecho positivo vigente en un determinado Estado, el cual describe, argumenta (elaborando conceptos doctrinales), interpreta (dilucidando su sentido y alcance) y sistematiza (reorganizando, coordinando y clasificando), sin perjuicio de contribuir a su aplicación, reforma y perfeccionamiento. En el fondo, la Sistemática Jurídica es el estudio dogmático o inmanente del Derecho positivo, predominantemente descriptivo pero con una finalidad profundamente pragmática, destinada a la aplicación y perfeccionamiento de su propio objeto formal de estudio: el ordenamiento jurídico en vigencia." (cursivas en el original) CELIS DANZINGER, "Relaciones entre Filosofía del Derecho, Ciencia Jurídica y Teoría del Derecho", cit. nota ${ }^{\circ}$ 9, p. 129.

${ }^{135}$ NÚÑEZ VAQUERO, “Ciencia Jurídica”, cit. nota n 9, pp. 610 y ss.

${ }^{136}$ ATIENZA, "La dogmática jurídica como tecno-praxis", cit. nota ${ }^{\circ}$ 9, pp. 189 y ss.

${ }^{137}$ VEGA “Las calificaciones del saber jurídico", cit. nota ${ }^{\circ} 4$, p. 392. 


\section{SCHURMANN, Miguel “¿Es científico el discurso elaborado por la dogmática jurídica? Una defensa de la pretensión de racionalidad del discurso dogmático elaborado por la ciencia del derecho penal”.}

conocimiento adquirido $^{138}$ y (ii) el denominado problema de la demarcación, esto es, qué teorías pueden ser calificadas como científicas. Dando cuenta con ello de la pretensión de racionalidad que lleva inserto el discurso dogmático. Cuando la actividad realizada por la dogmática jurídica se define como científica, generalmente se tiene en mente entonces un parámetro en virtud del cual pueda evaluarse como válido tanto el conocimiento producido como la pertenencia de los enunciados formulados a la dogmática jurídica como práctica, y en esa medida coincide con la idea de un saber racional riguroso. ${ }^{139}$

Para dilucidar la implicancia de la atribución de carácter científico a la dogmática jurídica primero debe ser explicitado cuál es la perspectiva teórica adoptada para realizar dicho juicio. Los intentos para dilucidar lo apropiado de la relación de sinonimia habitualmente atribuida a la dogmática y ciencia jurídica han sido numerosos en los últimos años y básicamente han sido dirigidos en dos direcciones. La primera de ellas ha propuesto ajustar el discurso dogmático a los requerimientos metodológicos o epistemológicos de las teorías científicas en el ámbito empírico. La segunda, por su parte, ha intentado describir verosímilmente la labor realizada por la dogmática para luego evaluar si dicha práctica realizada de una manera racional y metódica puede ser calificada como científica (distanciándose del paradigma clásico para las ciencias empíricas) o si resulta más apropiado emplear otro término para dar cuenta adecuadamente de su pretensión de validez. $^{140}$

\subsection{Posturas que evalúan la cientificidad del discurso dogmático a partir de su correspondencia en algún nivel con la práctica científica en el ámbito empírico}

Núñez, al formular una crítica al modelo de ciencia jurídica interpretativa postulado por Schiavello, sostiene que la cientificidad constituye un "sello de calidad" o de fiabilidad del conocimiento elaborado por la práctica que se pretende como científica. Para luego sostener que la calificación como científico de un tipo de actividad teórica no se debería a la asunción de un determinado método, como erróneamente se critica al monismo metodológico, sino que a una aspiración epistemológica. El prestigio de la actividad científica vendría dado por la capacidad explicativa (que Núñez lo asocia a una idea predictiva) como resultado de la disciplina. Con ello, en opinión de Núñez, si la dogmática jurídica quisiera alcanzar el estatus epistemológico de las ciencias debiera dedicar su estudio al análisis de las motivaciones e intereses de los jueces y cómo ello influye en lo que los tribunales de justicia reconocen como derecho obligatorio, de modo de poder describir predictivamente -de modo relevante para la acción- cuál será la decisión de los

\footnotetext{
${ }^{138}$ Ya sea vinculado a (i) una fuente determinada como en el Positivismo Lógico, (ii) una conjetura sometida a refutación y no refutada a la fecha de acuerdo a la teoría popperiana, (iii) a la aceptación de la comunidad científica como paradigma vigente, como en el programa historiográfico de Kuhn; (iv) o como un programa de investigación dogmático que no haya sido refutado y se muestre como irreversiblemente regresivo, bajo la teoría de Lakatos.

${ }^{139}$ VEGA “Las calificaciones del saber jurídico", cit. nota ${ }^{\circ} 4$, p. 378.

${ }^{140}$ Ambas aproximaciones tienen tanto pretensiones descriptivas (que es lo que hacen efectivamente los dogmáticos), como prescriptivas (qué es lo que deben hacer los dogmáticos para calificar su labor como científica o racional en un sentido más amplio), por lo que no es posible distinguirla bajo dicho baremo.
} 
tribunales para un determinado supuesto de hecho con relevancia jurídica. ${ }^{141}$ Esta es precisamente la forma de hacer dogmática jurídica propia del realismo norteamericano, que propone observar Matus cuando analiza críticamente la cuestión de "por qué citamos a los alemanes". ${ }^{142}$

El problema de esta propuesta es que no se refiere solo a un cambio del tipo de conocimiento que puede entregar la dogmática jurídica a la sociedad, sino que un completo cambio del objeto de estudio (desde las disposiciones legales que conforman el sistema jurídico a las sentencias y las motivaciones reales que poseen los jueces al dictarlas) y la metodología empleada (pasando desde el estudio a través de la metodología jurídica y propuestas normativas de interpretación de las disposiciones, a la observación y descripción de regularidades en la dictación de sentencias). Con ello, más allá de que los eventuales personas naturales que realicen la investigación puedan ser los mismos, la pregunta es qué quedaría de la práctica de la dogmática jurídica tal como se comprende por los partícipes de ella. La respuesta para nuestro medio probablemente es nada. ${ }^{143}$ La propuesta de ciencia jurídica no contiene el mínimo grado de verosimilitud como reconstrucción razonable de lo que hacen los juristas en nuestra tradición cultural. ${ }^{144}$

Otra vía seguida para analizar la cientificidad de la dogmática jurídica es la realizada por Bernasconi Ramírez. Para emprender su labor afirma un concepto de dogmática que sea generalmente descriptivo de lo que los juristas hacen cuando estudian normas positivas, de modo que permita identificar los rasgos comunes que existen entre las ciencias naturales y las que denomina 'humanas', y así fijar el conjunto de condiciones de la cientificidad de su saber. ${ }^{145}$ A su entender, lo que distingue a la cientificidad como saber, es la refutabilidad de sus proposiciones. A partir de allí se preocupa especialmente del denominado problema de la demarcación, postulando un esquema evaluativo de la 'cientificidad' de las teorías dogmáticas, determinando cuál manifestación de ellas puede ser calificable como científica. La cientificidad de las proposiciones no viene dado por la contrastación empírica de los enunciados, como lo sostendría un errado monismo metodológico, sino que por el escrutinio de la comunidad de especialistas, en un sentido kuhniano. En el caso de que las

\footnotetext{
${ }^{141}$ NÚÑEZ VAQUERO, "Sobre 'algunos argumentos", cit. nota n ${ }^{\circ} 63$, pp. 505 y ss.

${ }^{142}$ MATUS ACUÑA "Por qué citamos a los alemanes", cit. nota n 8, pp. 335 y ss.

${ }^{143}$ La falta de correspondencia entre nuestra tradición cultural y el modelo de ciencia jurídica propuesto por Núñez y Matus, sin embargo, no es ignorado por ellos. Mientras Núñez efectivamente reconoce que la ciencia jurídica es mayoritariamente ejercida bajo una comprensión argumentativista. NÚÑEZ VAQUERO, "Ciencia Jurídica", cit. nota ${ }^{\circ}$ 9, p. 625. Matus reconoce que efectivamente mayoritariamente citamos alemanes antes que, por ejemplo, anglosajones. Lo que parece no apreciar Matus, al contrario, es que la respuesta a la pregunta formulada (¿por qué citamos alemanes?), también admite como respuesta el hecho de que los alemanes entienden a la actividad de la dogmática jurídica bajo el mismo ideal con el que es comprendida la práctica por nuestra comunidad cultural, lo que justifica también nuestra atención hacia ellos. De hecho el fecundo trabajo dogmático realizado por Matus se relaciona de forma mucho más cercana con este modelo.

${ }^{144}$ ATIENZA, "La dogmática jurídica como tecno-praxis", cit. nota n 9, p. 179; de hecho van Weezel sostiene que el conocimiento producido en esos términos es el que le interesa a los litigantes, en tanto presentan una orientación estratégica hacia el derecho, que se diferencia de la comprensiva e imparcial que pretende la dogmática (VAN WEEZEL, “¿Por qué no citamos más (por ejemplo, a los alemanes)? Réplica a J. P. Matus", cit. nota $\mathrm{n}^{\circ} 32$, p. 2), sin embargo, ese es precisamente el conocimiento al que le otorga valor Núñez.

${ }^{145}$ BERNASCONI RAMÍREZ, “El carácter científico”, cit. nota n 5, p. 13.
} 


\section{SCHURMANN, Miguel “¿Es científico el discurso elaborado por la dogmática jurídica? Una defensa de la pretensión de racionalidad del discurso dogmático elaborado por la ciencia del derecho penal".}

comunidades científicas sean pequeñas o de escaso valor crítico, Bernasconi propone recurrir a una audiencia universal. ${ }^{146}$ Así, sólo sería posible testear una teoría dogmática local ante una audiencia universal, en la medida que ella se vincule a una problemática local, pero que sea extrapolable a otros sistemas jurídicos. Dichas características son observadas por Bernasconi en un trabajo realizado por un penalista chileno que cita a dogmáticos alemanes.

Más allá de la probable pertinencia de la cita a autores extranjeros en un artículo que analiza, ya sea un problema interpretativo que se presenta en la generalidad de los sistemas jurídicos con independencia de su regulación concreta, como lo son en general los problemas de la parte general del derecho penal, ${ }^{147}$ o en un problema interpretativo de una regulación históricamente dependiente de la realizada en otro contexto cultural, como resulta de la mayoría de la legislación nacional dictada en el siglo XIX, en referencia principalmente a la española, no parece razonable calificar como acientífico, irracional o como la mera afirmación de preferencias interpretativas subjetivas la formulación de una propuesta interpretativa del derecho vigente nacional por el mero hecho de no citar a autores extranjeros o no plantear un problema de alcance universal, en los términos planteados por Bernasconi. Situar como requisito de cientificidad la cita a autores extranjeros no se condice tampoco con la comprensión ideal de la dogmática por parte de los partícipes de ella, ni constituye un requisito que pueda ser fundado en buenas razones y, por ello, ser aceptado racionalmente como un parámetro normativo al que deba ser sometido la práctica.

Resulta interesante hacer notar que justamente lo que transforma el trabajo dogmático en científico, bajo la propuesta de Bernasconi, es precisamente lo que objeta Matus como una de las causas de la falta de comprensión de nuestro propio sistema jurídico, la búsqueda de argumentos de autoridad en autores alemanes, cuya práctica argumentativa se encuentra ante la disyuntiva de tener una vinculación local que impide ser extrapolada a la nuestra o que contiene una formulación tan abstracta que resulta inadecuado para comprender nuestra regulación legal. ${ }^{148}$

El problema que plantean estas posturas es la reducción de la práctica dogmática de modo que ellas en algún nivel sean parecidas a la práctica científica, sin evaluar el real valor de la práctica dogmática para la racionalidad del derecho vigente. La dogmática jurídica no se reduce en caso alguno a enunciados meramente descriptivos y predictivos sobre las sentencias que serán dictadas por los tribunales, sino que a proponer la sentencia que debe

\footnotetext{
${ }^{146}$ Peña es crítico no del tamaño, sino que de la actitud metodológica y principalmente ética de nuestra práctica dogmática, para los efectos de aspirar a ser calificada como científica. PEÑA GONZÁLEZ, "El Valor Científico del Derecho", cit. nota ${ }^{\circ} 115$, p. 37.

${ }^{147}$ En este sentido van Weezel reconoce también la dilucidación del sentido y alcance del carácter accesorio que presenta la punibilidad del cómplice e inductor. VAN WEEZEL, “¿Por qué no citamos más (por ejemplo, a los alemanes)? Réplica a J. P. Matus", cit. nota $\mathrm{n}^{\circ} 32$, p. 3.

${ }^{148}$ MATUS ACUÑA “Por qué citamos a los alemanes”, cit. nota n ${ }^{\circ}$ 8, pp. 315 y ss. Una respuesta crítica al estudio metodológico realizado por Matus se encuentra en VAN WEEZEL, ¿Por qué no citamos más (por ejemplo, a los alemanes)? Réplica a J. P. Matus”, cit. nota $n^{\circ} 32$, pp. 1 y ss.
} 


\section{Polít. crim. Vol. 14, No 27 (Julio 2019), Art. 16, pp. 549-598 [http://politcrim.com/wp-content/uploads/2019/06/Vol14N27A16.pdf]}

ser dictada y criticar en caso de que ella no sea correcta. ${ }^{149}$ Con ello la tarea del dogmático no se dirigiría a proponer la interpretación y aplicación correcta del derecho, sino que a predecir la sentencia que será realmente dictada por los tribunales, con independencia de su corrección. Dejando como un sinsentido discursivo una crítica jurisprudencial, ya que el dogmático no tendría una expectativa normativa sobre lo que es el derecho en una sociedad, sino que una expectativa cognitiva que será modificada acríticamente en la medida que la interpretación y aplicación del derecho cambie por parte de los tribunales. Por otra parte, tampoco es posible reducir la actividad dogmática a aquella fracción de problemas que pueden ser considerados como universales o que merezcan la atención más allá de nuestras fronteras. La corrección interpretativa de una disposición del derecho vigente chileno es un objeto idóneo para la dogmática jurídica, y su valor racional no puede ser descartado por el mero hecho de no responder a los patrones entregados por Núñez y Bernasconi.

En contra de una reconversión de la dogmática en los términos propuestos por Núñez y Matus, es necesario primero comprender y dar cuenta adecuadamente de las pretensiones de racionalidad del discurso dogmático, para lo que no necesitamos incluir más datos empíricos en el análisis, sino que primordialmente realizar una ordenación correcta de lo ya conocido. $^{150}$

\subsection{Una verosímil descripción de las funciones de la dogmática como presupuesto evaluativo de su racionalidad}

Ajustar una práctica argumentativa al modelo evaluativo de otro, para así asegurar la pretensión de validez de su práctica, no puede ser la vía idónea para dirigir un análisis sobre su racionalidad. La pregunta sobre la cientificidad de la dogmática jurídica siempre puede ser planteada delimitando el objeto de lo que se compara con el parámetro utilizado para su evaluación. Qué se entiende por dogmática o ciencia jurídica por una parte, y cuál es el parámetro de cientificidad que se utiliza para ver si la práctica satisface dicho estándar son los dos extremos de la pregunta. Así el carácter científico del derecho puede ser afirmado sin dificultades si la noción de ciencia utilizado es aquel previsto por la tradición kantiana de pensamiento que entiende como científico la ordenación sistemático del conocimiento. ${ }^{151}$ Al contrario, si se evalúa la actividad característica de la dogmática jurídica con el método o con el conocimiento que es generado por otro tipo de práctica argumentativa la discrepancia será evidente y el callejón no tendrá salida, como quedó claro precedentemente. Esto se debe a que la pregunta asume un sesgo descriptivo, obliga a realizar una comparación de distintas actividades argumentativas que de esa forma resultan inconmensurables entre sí.

\footnotetext{
${ }^{149}$ Esta diferencia podría ser pasada por alto si se define la actividad de la dogmática jurídica como de sentencia ferenda, ya que bajo dicha denominación puede ser (mal) entendida no sólo la propuesta interpretativa que es sostenida como correcta por el dogmático, sino que también la descripción predictiva que realiza un estudioso del derecho bajo el paradigma del realismo jurídico.

${ }^{150}$ WITTGENSTEIN, Philosophische Untersuchungen. cit. nota $\mathrm{n}^{\circ} 72, \mathrm{p} .81$.

${ }^{151}$ VEGA "Las calificaciones del saber jurídico", cit. nota $\mathrm{n}^{\circ} 4$, pp. 388. Con mayor razón la cientificidad de la dogmática puede ser afirmada si el objeto de comparación ya no es las ciencias empíricas, sino que otro más improbable como la magia o la ordalía (p. 379).
} 


\section{SCHURMANN, Miguel “¿Es científico el discurso elaborado por la dogmática jurídica? Una defensa de la pretensión de racionalidad del discurso dogmático elaborado por la ciencia del derecho penal".}

La conmensurabilidad de la racionalidad de prácticas diversas exige tanto la adopción de parámetros neutrales, como la realización del análisis comparativo en un nivel más elevado, no ya de los enunciados propio de las aplicaciones pretendidas, sino que en el de los presupuestos teóricos y metodológicos de las teorías. Mediante esta estrategia teórica se intenta demostrar que la visión que la filosofía de las ciencias ha desarrollado en los últimos años se ha caracterizado por el abandono de una racionalidad en sentido fuerte, demostrando que las teorías científicas no sólo contienen enunciados descriptivos, sino que también, decisiones normativas y valorativas, lo que las asemeja bastante a las características de lo que solemos entender como teorías dogmáticas. ${ }^{152}$ Así, la noción ingenua de las teorías científicas no constituiría un parámetro real de evaluación de racionalidad, tal como quedó en evidencia al concluir el capítulo $3 .{ }^{153}$

Sólo tomando en cuenta la especificidad del discurso dogmático, se puede plantear adecuadamente la pregunta por la racionalidad de su método y la validez del conocimiento generado a través de él. En nuestro medio se ha reflexionado sobre el valor científico de la labor realizada por la dogmática, partiendo por una descripción de ella. Así, para Bascuñán "el objetivo de la dogmática jurídica es el análisis y reconstrucción del Derecho vigente, con el propósito práctico de anticipar la solución correcta desde la perspectiva del Derecho vigente a cualquier caso de relevancia jurídica". ${ }^{154}$ Por su parte, para Peña "identificar normas, sistematizarlas, interpretarlas, optimizar el conjunto de sus consecuencias, son, dicho someramente, las labores habituales de la dogmática". ${ }^{155} \mathrm{El}$ conocimiento que esta labor le entrega a la comunidad entonces no se encuentra referido a la anticipación de la sentencia que efectivamente será dictada por un determinado tribunal, sino que la anticipación de la sentencia que debiese ser dictada, en el evento que la descripción del caso sea conceptual y selectivamente subsumible dentro del supuesto de aplicación descrito en la propuesta interpretativa. Así, la noción de sentencia ferenda conserva su sentido racional y potencial crítico.

Con ello, los parámetros de evaluación de la racionalidad del conocimiento teórico generado por la dogmática jurídica deben adaptarse al ideal crítico. Por ejemplo, para Peña, el carácter científico del razonamiento dogmático dependerá de que cada comunidad teórica satisfaga ciertos requisitos, a saber, "control racional de sus opiniones, la contrastación con

\footnotetext{
${ }^{152}$ Una postura que adopta correctamente esta orientación es la propuesta de Juan Cofré, quien pretende aplicar al conocimiento dogmático los avances metodológicos llevados a cabo en el ámbito de la filosofía de las ciencias y en la filosofía hermenéutica. Así, propone asumir el fracaso del ideal del racionalismo llevado adelante por el Positivismo Lógico. Sin embargo, el abandono del racionalismo no implica un abandono de la racionalidad como pretensión válida del discurso. Para este autor "Las ciencias del espíritu -y la ciencia jurídica especialmente- no han evolucionado conforme a estos descubrimientos y, naturalmente, es de esperar que, aceptando los resultados de la razón crítica, se reorienten utilizando nuevos métodos hacia la comprensión más plausible de sus objetos de estudio" (p. 57). De esta forma, Cofré propone evaluar la pretensión de racionalidad de la dogmática desde un racionalismo crítico, como el propuesto por Habermas. COFRÉ, Juan. "Racionalidad en el Derecho. Una aproximación filosófica a la hermenéutica jurídica", Revista Chilena de Derecho, Volumen 22 NN $^{\circ}$, 1995, pp. 41-59.

${ }^{153}$ En un sentido semejante PEÑA GONZÁLEZ, "El Valor Científico del Derecho”, cit. nota n 115 , pp. 36 y ss.

${ }^{154}$ BASCUÑÁN RODRÍGUEZ, “Observaciones sobre la ciencia del derecho”, cit. nota n 7, p. 17.

${ }^{155}$ PEÑA GONZÁLEZ, “El Valor Científico del Derecho”, cit. nota n 115, p. 33.
} 


\section{Polít. crim. Vol. 14, No 27 (Julio 2019), Art. 16, pp. 549-598 [http://politcrim.com/wp-content/uploads/2019/06/Vol14N27A16.pdf]}

principios comúnmente admitidos y el uso de un cierto procedimiento de justificación de sus resultados. La ciencia es, ante todo, una actividad ética referente al uso del lenguaje y la razón". ${ }^{156}$ Una descripción de la estructura y función de las teorías dogmáticas, aplicando modelos teóricos de la filosofía de las ciencias, propone Canaris, como criterios evaluativos de las teorías dogmáticas, al definir sus funciones "en los siguientes términos: permite la clasificación conceptual y/o dogmática de la(s) correspondiente(s) solución(es) del (de los) problema(s), asegura su compatibilidad con el sistema del Derecho vigente, clarifica su contenido material de justicia, y aporta un marco para la solución de (otros) problemas. Al mismo tiempo, se hallan también aquí, consecuentemente, los más importantes criterios para valorar la eficacia de una teoría jurídica". ${ }^{157}$

Una descripción de teorías dogmáticas y de los parámetros de evaluación de las mismas en el sentido que aquí se ha desarrollado permite utilizar de forma análoga el estándar previsto por Imre Lakatos para la metodología de los programas de investigación científica. La adecuación analógica consiste precisamente en convertir la metodología de los programas de investigación científica a la particularidad que presenta la argumentación jurídica y, en especial, para las teorías dogmáticas, de modo que la evaluación se realice con los parámetros de una metodología de los programas de investigación dogmática. Como ya se ha señalado previamente, ${ }^{158}$ este esquema teórico propone una evaluación retrospectiva de la racionalidad del cambio teórico, por medio de un análisis diacrónico entre la progresividad o regresividad que presenta dicha teoría en tanto secuencia en relación a su contenido actual y potencial aclaratorio del derecho vigente. A partir de ello podrá ser evaluado si la sucesión de los programas de investigación dogmáticos, previamente demarcados, responden a razones y, por ello, constituyen el correlato de la pretensión de racionalidad discursivamente desempeñada por parte de las teorías dogmáticas, o si dicha sucesión responde al cambio de preferencias subjetivas de la comunidad dogmática. ${ }^{159}$

\footnotetext{
${ }^{156}$ PEÑA GONZÁLEZ, "El Valor Científico del Derecho", cit. nota $n^{\circ} 115$, p. 37. Siguiendo a Rorty, el profesor Peña asume un significado de ciencia y racionalidad desprendido del método, propone un modelo de racionalidad como ejercicio de ciertas virtudes, "a fin de cuentas, éticas: tolerancia, respeto a las opiniones, disposición a escuchar, recurso a la persuasión antes que a la fuerza" (p. 37), destacando el valor e intentando asimilar a la labor de la dogmática jurídica a este sentido de racionalidad

${ }^{157}$ CANARIS, Función, estructura y falsación de las teorías jurídicas, cit. nota n 12 , pp. 35 y ss.

${ }^{158}$ Ver supra 3.1.3

${ }^{159}$ Este modelo evaluativo contradice la intuición de situar a los tribunales de justicia como instancia idónea para adjudicar una disputa dogmática, dado que ella sería un indicador suficiente de la racionalidad de una teoría dogmática que se pretende verosímil y correcta, en la medida que ella sólo triunfaría en el campo teórico si su solución propuesta es la adoptada finalmente para interpretar el derecho vigente, constituyéndose así como un parámetro objetivo para evaluar el éxito de una propuesta teórica-dogmática, en los términos exigidos por Núñez. (Ver NÚÑEZ VAQUERO, "Dogmática jurídica", cit. nota ${ }^{\circ} 2$, pp. 250 y s.) Sin embargo, dicho método de adjudicación es aquí expresamente rechazado. Una evaluación particular de una teoría dogmática, restringida a sólo un ámbito de aplicación de ésta, puede tener una serie de inconvenientes: (i) puede resultar extremadamente contingente e incompleto, al ignorar tanto el carácter no necesariamente unificado de aplicación del derecho (p. e. distintos tribunales -y/o jueces dentro de un tribunal- pueden adherir a distintas teorías), así como el carácter dinámico de dicha evaluación (pudiendo variar temporalmente quién puede ser identificado como triunfador de un debate dogmático); (ii) sin embargo, la razón principal radica en la inadecuación de situar a los tribunales como instancia dirimente, dado que dicha institución se caracteriza por decidir un conflicto jurídico particular cuyo conocimiento fáctico e instancia de deliberación esta delimitado tanto temporal y como cognoscitivamente. La judicatura no tiene ni nunca podría tener como función adjudicar una postura dogmática, en especial porque ella solo podría llegar a situar bajo su espectro
} 


\section{SCHURMANN, Miguel “¿Es científico el discurso elaborado por la dogmática jurídica? \\ Una defensa de la pretensión de racionalidad del discurso dogmático elaborado por la ciencia del derecho penal".}

\subsection{La aplicación del modelo. La sucesión de programas de investigación dogmáticos en el derecho penal como progreso teórico}

Si ahora se realiza un análisis comparativo de lo que, por un parte, la teoría de Lakatos formula como programa de investigación científico -aceptando la asunción racional de los fundamentos y premisas teóricas y metodológicas que constituyen el núcleo firme del programa- y, por la otra, la autocomprensión de los estándares de cientificidad postulados por la dogmática jurídico penal y su desarrollo histórico, las similitudes se reflejan con mayor facilidad. La dogmática penal alemana ha trabajado históricamente bajo diversos programas de investigación dogmática que se han sucedido en el tiempo en los últimos doscientos años, los cuales han sido recibidos y adecuados a nuestra tradición cultural por distintas vías. ${ }^{160}$ Así de una teoría del delito causalista (clásica y neoclásica) se pasó a una teoría del delito finalista y luego a una funcionalista. ${ }^{161}$ Por cierto es posible observar períodos de coexistencia de programas de investigación, entre la emergencia y obsolescencia de ellos. Esta sucesión histórica está lejos de ser asumida por la práctica como un mero cambio en la ordenación de los elementos del juicio de imputación de responsabilidad penal o una modificación de las creencias - no racionales- bajo las cuales trabajaban los dogmáticos de cada época. ${ }^{162} \mathrm{Al}$ contrario, en todos los casos el cambio teórico ha sido calificado como racional, dado que la teoría sucesora tuvo un mayor poder explicativo y heurístico que la antecesora, en los términos previstos por Lakatos. Los ejemplos a este respecto son abundantes, por ello es útil transcribir la opinión que sostiene Roxin en dicho sentido, refiriéndose a la contribución del finalismo para la dogmática penal alemana.

de análisis una determinada pretensión particular de aplicación de la teoría, y no su completa configuración, lo que impide realizar una valoración global de ésta, pudiendo extraer conclusiones provisorias y de carácter contradictorio en caso de adjudicaciones parciales. Asimismo, una evaluación a partir de una solución particular impide apreciar la evolución y contenido heurístico de la teoría, lo que la sitúa como un modelo explicativo del desempeño de racionalidad de la práctica dogmática de menor calidad frente a la aquí favorecida. Al contrario, es decir, a favor de situar a la jurisprudencia como instancia que confirma o refuta una teoría dogmática, ver VEGA "Las calificaciones del saber jurídico", cit. nota n 4, p. 398. Finalmente, la inadecuación de dicho parámetro también se puede argumentar si se acoge el riesgo detectado por Schünemann relativo a que "la jurisprudencia selecciona, a partir de allí, de entre las innumerables variantes dogmáticas, como si se tratara de una tienda con mercaderías variadas, el esbozo que casualmente se ajusta al resultado deseado" y no necesariamente el correcto. SCHÜNEMANN "El propio sistema de la teoría del delito", cit. nota $n^{\circ} 124$, p. 10. Sin embargo, el mismo Schünemann -en otra instancia- califica como éxito del finalismo el haber sido acogido por parte del Tribunal Federal alemán una aplicación pretendida de su teoría, esto es, que el error de prohibición no provoca la exclusión del dolo. SCHÜNEMANN, "Introducción al pensamiento sistemático en Derecho Penal", cit. nota $n^{\circ} 31$, p. 57.

${ }^{160}$ Matus da cuenta de la recepción del finalismo a través de la traducción del manual de Welzel por parte de los jóvenes profesores, en aquel entones, Juan Bustos y Sergio Yáñez. MATUS ACUÑA, "Por qué citamos a los alemanes", cit. nota ${ }^{\circ} 8$, p. 312.

${ }^{161}$ En este sentido WILENMANN VON BERNATH, “Conocimientos especiales”, cit. nota n 69, p. 137. La sucesión analítica de programas es descrita por SCHÜNEMANN, "Introducción al pensamiento sistemático en Derecho Penal", cit. nota ${ }^{\circ} 31$, pp. 43 y ss.

${ }^{162} \mathrm{O}$ bien, haciendo referencia a la escéptica metáfora del cocinero (ver supra nota 111), un mero cambio de los gustos o preferencias subjetivas de los partícipes de la práctica. 


\section{Polít. crim. Vol. 14, № 27 (Julio 2019), Art. 16, pp. 549-598 [http://politcrim.com/wp-content/uploads/2019/06/Vol14N27A16.pdf]}

En Alemania ya no supone un tema de discusión actual, sino más bien forma parte ya de la historia de la Dogmática. Hoy en día, ya ningún joven penalista alemán se describiría a sí mismo como Finalista.

Aun así, la doctrina final de la acción ha dejado tras de sí hondas y perdurables huellas en la Dogmática jurídico-penal. En este sentido, supuso en contraposición con la precedente época del pensamiento sistemático del Derecho penal en Alemania, la así llamada teoría causal de la acción, un avance esencial, en la medida en que, en vez de un mero nexo lógico-causal -la condicio sine qua non-, recurrió a una categoría antropológica para la fundamentación de la responsabilidad penal: el poder configurador de los acontecimientos mediante la finalidad humana. El consecuente reconocimiento del dolo como parte del tipo subjetivo y la comprensión de que el injusto penal se compone no solo de un desvalor del resultado, sino también del desvalor de la acción, son todavía hoy en Alemania planteamientos absolutamente dominantes. Las consecuencias prácticas de este pensamiento han influido igualmente en dos puntos esenciales de la nueva parte general del Código penal alemán de 1975. La distinción entre error de tipo y error de prohibición y su tratamiento absolutamente divergente -mientras que el error de tipo excluye el dolo, en el error de prohibición éste subsiste y solo cuando el error es invencible conduce a la exclusión de la culpabilidad- fueron introducidas por la teoría de la acción final y asumidas por el legislador alemán ( $\$ 16,17 \mathrm{StGB})$. Lo mismo puede decirse respecto de la decisión del legislador de que solo quepa la participación en un hecho doloso ( $\S 26,27 \mathrm{StGB}$ ); ello se corresponde con la tesis de que la participación presupone un hecho principal típico y que este hecho incorpora el dolo. ${ }^{163}$

La cita precedente es bastante elocuente. Si bien Roxin califica al programa de investigación dogmático finalista como abandonado, ello no impide reconocer históricamente- en él un avance esencial en la ciencia del derecho penal alemán. ${ }^{164} \mathrm{El}$ abandono del programa de investigación finalista por parte de los dogmáticos, no se debe al mero cambio de métodos evaluativos y fundamentos inconmensurables entre sí, como lo sostiene Kuhn, sino que debido a razones, las que son identificadas por Roxin como la debilidad explicativa que dicho programa de investigación presentaba tanto en algunas áreas de aplicación relevante de la teoría general del delito, como en la validez de su fundamentación teórica. Según Roxin, el abandono del programa se debió fundamentalmente a las siguientes razones:

Simplemente quiero señalar de forma resumida los que a mi parecer son los tres motivos fundamentales por los que la teoría de la acción final, pese a sus éxitos y ventajas en conjunto, no se ha impuesto. En primer lugar, los delitos imprudentes no pueden ser explicados a partir de la finalidad del actuar del autor, puesto que el resultado típico precisamente no está sujeto al control final del autor. En segundo lugar, la teoría de la acción final fracasa también en los delitos omisivos, dado que el omitente no controla ningún curso causal, sino que precisamente lo que se le reprocha es el no intervenir en un curso causal que tiene lugar con independencia de él. Y en tercer lugar, cabe objetar frente a la teoría de la acción final que, como es

\footnotetext{
${ }^{163}$ ROXIN, "El nuevo desarrollo", cit. nota ${ }^{\circ} 34$, p. 3.

${ }^{164}$ De acuerdo con el progreso científico que significo la adopción del finalismo SCHÜNEMANN, "Introducción al pensamiento sistemático en Derecho Penal", cit. nota n 31, p. 56.
} 


\section{SCHURMANN, Miguel “¿Es científico el discurso elaborado por la dogmática jurídica? Una defensa de la pretensión de racionalidad del discurso dogmático elaborado por la ciencia del derecho penal".}

sabido, de circunstancias ontológicas, esto es, del mero ser (Sein), ya sea la causalidad o la finalidad, no cabe derivar ningún deber (Sollen). ${ }^{165}$

En opinión de Roxin, las debilidades comparativas en la capacidad explicativa de dicho programa -anomalías-, en relación con los desarrollados por los dogmáticos funcionalistas, han llevado a la emergencia y consolidación de este nuevo paradigma en la dogmática penal. ${ }^{166}$ El tratamiento de los delitos imprudentes y omisivos constituirían ámbitos del sistema penal para los cuales la teoría finalista no podría entregar una comprensión satisfactoria, presentándose como anomalías y su integración a la teoría finalista aparece por ello como un intento de inclusión de hipótesis ad-hoc. ${ }^{167}$ Dichas anomalías, el agotamiento de su capacidad para anticipar soluciones a nuevos problemas teóricos y la emergencia del funcionalismo explicarían el abandono del programa de investigación dogmático finalista.

Por su parte, el programa de investigación dogmático funcionalista (ya sea en la versión de Roxin o de Jakobs) estaría, en el parecer de Roxin, en un estado de ciencia madura (en términos de Lakatos) o normal (en términos de Kuhn) en la medida que la mayoría de los dogmáticos actualmente no trabajan para sustituir el programa, sino que para buscar nuevas aplicaciones del mismo para la mejor comprensión, sistematización y aplicación del derecho vigente. A diferencia de la noción de paradigma, que supone la hegemonía y exclusión en la investigación en períodos de ciencia normal, los programas de investigación dogmáticos se caracterizan por la tolerancia a una pluralidad de programas y por una aptitud constante hacia el debate y crítica de las teorías rivales. En este sentido, una de las características de la elaboración de teorías dogmáticas es la admisión amplia de programas rivales, sólo reconociendo como límite externo la necesaria verosimilitud de las construcciones teóricas en relación con el derecho vigente. Así, el progreso en la investigación dogmática, se desarrolla en una pluralidad de teorías en disputa por acreditar la corrección de sus postulados.

Más allá de la corrección de las críticas formuladas al finalismo y de su diagnóstico sobre el dominio del funcionalismo en la dogmática penal actual, ${ }^{168}$ el análisis de Roxin, ${ }^{169}$ que es

\footnotetext{
165 ROXIN, "El nuevo desarrollo", cit. nota n 34, p. 3.

${ }^{166}$ En sus propias palabras, "[p]or consiguiente, las concepciones actualmente dominantes en la doctrina del Derecho penal alemán no orientan su sistema a realidades ontológicas previas como la causalidad o la finalidad, sino a los cometidos y finalidades del Derecho penal. Se habla así de proyectos funcionalistas del sistema. Mientras que el causalismo y el finalismo compartían una base común consistente en su dependencia a fundamentos ontológicos, las teorías funcionalistas coinciden en su punto de partida normativo". ROXIN, "El nuevo desarrollo", cit. nota n 34, p. 4.

${ }^{167}$ Paradigmática resulta la insatisfactoria explicación de Welzel para la imprudencia desde el punto de vista de la teoría final de la acción, la cual es definida como la conducción final de la acción para realizar una actividad penalmente irrelevante (p. e. emprender el viaje de regreso a casa), siendo que lo relevante para el derecho penal radica precisamente en la falta de seguimiento de la norma de comportamiento (p. e. la que prohíbe lesionar a otro, previendo el sistema además deberes de cuidado específico para el tráfico rodado). SCHÜNEMANN, "Introducción al pensamiento sistemático en Derecho Penal”, cit. nota n 31, p. 58.

${ }^{168} \mathrm{La}$ exhaustividad de su apreciación es restringida si se omite el modelo de teoría de la imputación desarrollado por principalmente por Hruschka, cuyos orígenes con facilidad se remontan a la teoría de la imputación desarrollada por entre otros Pufendorf
} 


\section{Polít. crim. Vol. 14, № 27 (Julio 2019), Art. 16, pp. 549-598 [http://politcrim.com/wp-content/uploads/2019/06/Vol14N27A16.pdf]}

común en los manuales de derecho penal alemán y en cualquier revisión históricadogmática, tiene la virtud de reflexionar sobre la existencia de programas de investigación dogmática y el cambio teórico, asumiendo una postura racionalista, el cual refleja el sentido común que los practicantes de la comunidad dogmática le atribuyen a su labor cognoscitiva. La corrección de las teorías dogmáticas es evaluada en base a razones, con argumentos pretendidamente racionales, vinculados a la aplicación de la teoría como medio constructivo para satisfacer la pretensión de corrección propia del sistema jurídico, tanto en su fundamentación como en su aplicación, en tanto sistema coherente de reglas. Así, y ahora desde una perspectiva histórica, el sucesivo cambio teórico ha permitido un avance en la capacidad aclaratoria ${ }^{170}$ de la dogmática jurídico penal en su labor de sistematización y reconstrucción racional del sistema jurídico.

\section{Conclusiones}

En consecuencia, parece bastante claro que la pregunta -que ha de ser contestada binariamente- sobre si la dogmática jurídica puede ser calificada como científica, carece de interés teórico. Ella debe ser reformulada en el sentido proponer, a partir la perspectiva del partícipe, una descripción verosímil de lo que constituye una teoría dogmática y cómo ella contribuye a una comprensión racional del sistema jurídico, planteando las pretensiones de validez que son reconocibles en su formulación y reconstruyendo las condiciones racionales de su posibilitación. Dicho acercamiento teórico, que reconoce la prioridad tanto de las especiales características del objeto de análisis, como de la metodología empleada en el análisis dogmático, permite en primer lugar determinar cuáles son las características que debe reunir una propuesta interpretativa del derecho vigente para ser calificado como una teoría dogmática, entregando con ello una respuesta al tradicional problema de la demarcación, y, en segundo lugar, establecer un parámetro normativo para determinar si la sucesión de programas de investigación dogmático se debe a un progreso teórico. Un análisis de la autocomprensión de la dogmática penal demuestra la existencia de evidentes pretensiones de validez tanto en la formulación de las teorías dogmáticas como en la formulación de los estándares de racionalidad de la práctica.

Así, una verosímil comprensión de la práctica dogmática desde la perspectiva teórica del partícipe permite afirmar que el carácter científico de las teorías dogmáticas dependerá de

\footnotetext{
"Zurechnung seit Pufendorf", cit. nota ${ }^{\circ}$ 120, pp. 17-27; y en el mismo sentido previamente HRUSCHKA, "Puede y debería ser sistemática la dogmática jurídico-penal?", cit. nota n 120, p. 362). Y si se considera también el modelo de teoría de las normas fundado por Kindhäuser y Vogel, y desarrollado entre nosotros por Mañalich. Por su parte, en cuanto a las anomalías detectadas en el paradigma funcionalista dominante, un ejemplo de ello se encuentra en la impugnación que ha recibido la teoría de la imputación objetiva especialmente en el tratamiento que le otorga a los conocimientos especiales del autor, lo que podría fácilmente ser catalogado como una anomalía de la teoría, cuya tratamiento actual constituye una hipótesis ad-hoc que demostraría -en retrospectiva y comparativamente con su rival- el carácter regresivo del programa. Para revisar la certera crítica a la teoría de la imputación objetiva es fundamental ver KINDHÄUSER, Urs. "El tipo subjetivo en la construcción del delito", Indret 4/2008, pp. 1 - 35. En http://www.indret.com/pdf/579_es.pdf [visitado 22.03.2018].

${ }^{169}$ El que se encuentra a su vez secundado de forma temporalmente más amplia en SCHÜNEMANN, "Introducción al pensamiento sistemático en Derecho Penal", cit. nota n 31 , pp. 43 y ss.

${ }^{170}$ Kindhäuser eleva correctamente a factor decisivo para la evaluación de una teoría dogmática su fuerza aclaratoria. KINDHÄUSER “Die deutsche Strafrechtsdogmatik”, cit. nota n 20, p. 960.
} 
la aceptación racional de la pretensión de corrección inserta en sus discursos de aplicación de reglas, la satisfacción del estándar o parámetro que se establezca como criterio de reconocimiento (demarcación) de las teorías dogmáticas y una justificación racional del cambio teórico como forma de validación (por la vía de la falsación) del conocimiento teórico entregado por la dogmática para la comprensión del sistema jurídico. Un análisis comparativo para la dogmática jurídico penal reafirma la satisfacción de su pretensión de racionalidad, en tanto las teorías dogmáticas se han conformado y comportado históricamente de forma análoga a los programas de investigación científicos descritos por Lakatos para el ámbito de la filosofía de las ciencias, bajo una comprensión de los mismos que permita la conmensurabilidad de prácticas argumentativas diversas.

\section{Bibliografía}

ALBERT, Hans, Conocimiento y derecho. La jurisprudencia a la luz del criticismo, Barcelona: Paidos, 2002.

ALEXY, Robert, Teoría de la Argumentación Jurídica, Madrid: editorial,1989.

ALEXY, Robert, "La tesis del caso especial", Isegoría, $\mathrm{N}^{\circ} 21$ (año), pp. 23-35, disponible en http://isegoria.revistas.csic.es/index.php/isegoria/article/viewFile/75/75 [visitado el 22.03.2018].

ATIENZA, Manuel, "La dogmática jurídica como tecno-praxis", En: Modelando la ciencia jurídica, NUÑEZ, Álvaro (Coord.), Lima: Palestra Editores, 2014. pp. 169-196. En https://archivos.juridicas.unam.mx/www/bjv/libros/8/3825/10.pdf [visitado el 22.03.2018].

BASCUÑÁN RODRÍGUEZ, Antonio. "Observaciones sobre la ciencia del derecho", Revista Derecho y Humanidades, $\mathrm{N}^{\circ} 6$ (1998), pp. 15-25. En https://revistas.uchile.cl/index.php/RDH/article/view/25785/27113 [visitado el 22.03.2018].

BERNASCONI RAMÍREZ, Andrés. "El carácter científico de la dogmática jurídica", Revista de Derecho Universidad Austral de Chile, Vol. 20, № 1 (2007), pp. 9-37. En: $\quad$ https://scielo.conicyt.cl/scielo.php?script=sci_abstract\&pid=S071809502007000100001\&lng=es\&nrm=iso [visitada el 22.03.2018].

CANARIS, Claus-Wilhem, Función, Estructura y Falsación de las teorías jurídicas, Madrid: Editorial Civitas, 1995.

CELIS DANZINGER, Gabriel, "Relaciones entre Filosofía del Derecho, Ciencia Jurídica y Teoría del Derecho", Revista de Derecho Escuela de Postgrado, № 1, (2011), pp. $111-150$.

COFRÉ, Juan. "Racionalidad en el Derecho. Una aproximación filosófica a la hermenéutica jurídica”. En: Revista Chilena de Derecho. Volumen 22 № 1, (1995). pp. 41-59.

DWORKIN, Ronald. Los derechos en serio. Ariel, Barcelona, 1984

GARCÍA DE ENTERRÍA, Eduardo y MENÉNDEZ MENÉNDEZ, Aurelio. El Derecho, la Ley y el Juez dos estudios. Civitas. Madrid, España, 1990.

GRECO, Luis. "Dos formas de hacer dogmática jurídico-penal”, Revista Discusiones No 8. Páginas 177-181. Disponible en http://www.cervantesvirtual.com/obra/dosformas-de-hacer-dogmtica-jurdicopenal-0/ [visitado el 22.03.2018].

GÜNTHER, Klaus. "Un concepto normativo de coherencia para una teoría de la 
argumentación jurídica", Doxa -Cuadernos de Filosofía del Derecho № 17-18, Universidad de Alicante, España, 1995. pp. 271-302.

GÜNTHER, Klaus. "Critical Remarks on Robert Alexy's 'Special-Case Thesis”. Ratio Juris. Vol. 6 No. 2, (1993). pp. 143-156.

HABERMAS, Jürgen. Facticidad y validez. Trotta. 1998.

HABERMAS, Jürgen. "Una polémica: Contra un racionalismo disminuido en términos positivistas”, en: La lógica de las ciencias sociales. Madrid: Tecnos, 1990, pp. 4570.

HABERMAS, Jürgen. "Ética del discurso. Un programa de fundamentación”. En: GARCÍA COTALERO, Ramón (Traductor), Conciencia moral y acción comunicativa. Barcelona. Península, 1983. pp. 59-134.

HARE, R.M. "Taxonomía”, en: Ordenando la Ética. Barcelona: Ariel, 1999. pp. 49 -69.

HRUSCHKA, Joachim. "Puede y debería ser sistemática la dogmática jurídico-penal?”. En SÁNCHEZ-OSTIZ, Pablo (edit.), Imputación y Derecho Penal. Editorial BdeF, 2009. pp. 333- 368.

JAKOBS, Günther. "El derecho penal como disciplina científica". Navarra. Thomson Civitas. 2008.

KINDHÄUSER, Urs. "El tipo subjetivo en la construcción del delito", Indret 4/2008. pp. 135. Disponible en http://www.indret.com/pdf/579 es.pdf [visitada el 22.03.2018].

KINDHÄUSER, Urs. Die deutsche Strafrechtsdogmatik zwischen Anpassung und Selbstbehauptung - Grenzkontrolle der Kriminalpolitik durch die Dogmatik. En: Zeitschrift für gesamte Strafrechtswissenschaft (ZStW), 2009, Heft 4. Páginas 954964.

KUHN, Thomas. "La estructura de las revoluciones científicas". Fondo de Cultura Económica. 1971.

KUHN, Thomas. "Segundos pensamientos sobre paradigmas". Tecnos. Madrid, 1978.

LAKATOS, Imre. "La metodología de los programa de investigación científica". Alianza Editorial. Madrid, España. 1983

LUHMANN, Niklas. "Sistema Jurídico y Dogmática Jurídica". Centro de Estudios Constitucionales. Madrid, España. 1983.

MATUS ACUÑA, Jean Pierre. "Por qué citamos a los alemanes y otros apuntes metodológicos". En: Derecho penal, criminología y política criminal en el cambio de siglo. Del mismo. Editorial Jurídica de Chile, 2011. pp. 311-347.

NÚÑEZ VAQUERO, Álvaro. "Dogmática Jurídica”, Eunomía. Revista en Cultura de la Legalidad, Número 6, marzo - agosto 2014. pp. 245-260. En http://eunomia.tirant.com/wp-content/uploads/2014/04/16-Eunomia6_NunezVaquero_final.pdf [visitada el 22.03.2018].

NÚÑEZ VAQUERO, Álvaro. "Sobre 'algunos argumentos a favor de una ciencia jurídica interpretativa' de Aldo Schiavello”. En: Doxa -Cuadernos de Filosofía del Derecho $\mathrm{N}^{\mathrm{o}}$ 38, 2015, pp. 501-524. Disponible en http://doxa.ua.es/article/view/2015-n38sobre-algunos-argumentos-a-favor-de-una-ciencia-juridica-interpretativa-de-aldoschiavello [visitada el 22.03.2018].

NÚÑEZ VAQUERO, Álvaro. "Ciencia Jurídica”. En: Enciclopedia de Filosofía y Teoría del Derecho, 2015, vol. 1, pp. 601-631. Disponible en https://archivos.juridicas.unam.mx/www/bjv/libros/8/3875/19.pdf [visitada el 22.03.2018]. 
PEÑA GONZÁLEZ, Carlos. "El valor científico del Derecho", Revista Derecho y Humanidades. Santiago, Chile. Número 6, (1998). pp. 31-38. En: https://revistas.uchile.cl/index.php/RDH/article/view/25781/27109 [visitado 22.03.2018].

POPPER, Karl. “Conjeturas y Refutaciones”.Paidos. Barcelona, 1972.

ROXIN, Claus. "El nuevo desarrollo de la dogmática jurídico-penal en Alemania, InDret 4/2012, $\quad$ pp. $\quad 1 \quad 24 . \quad$ En: http://www.raco.cat/index.php/InDret/article/view/260968/348124 [visitada el 22.03.2018].

SCHIAVELLO, Aldo. "Algunos argumentos a favor de una ciencia jurídica interpretativa", Doxa -Cuadernos de Filosofía del Derecho No 37, 2014, pp. 193 - 217. En http://doxa.ua.es/article/view/2014-n37-algunos-argumentos-a-favor-de-unaciencia-juridica-interpretativa [visitada el 22.03.2018].

SCHÜNEMANN, Bernd. "Introducción al pensamiento sistemático en Derecho Penal". En: El sistema moderno del derecho penal cuestiones fundamentales. Del mismo. Editorial Tecnos, Madrid, 1991. pp. 31 - 80.

SCHÜNEMANN, Bernd. "El propio sistema de la teoría del delito", Indret, 1/2008. pp. 1 20. En: http://www.indret.com/pdf/505.pdf [visitada el 22.03.2018].

SCHÜNEMANN, Bernd. "Standpunkte der deutschen Strafrechtslehrer zu den Zukunftsperspektiven der Rechtswissenschaft und der akademischen juristischen Ausbildung in Deutschland" En: Zeitschrift für Internationale Strafrechtsdogmatik (ZIS). $\quad \mathrm{N}^{\circ}$ 6/2012. pp. 302 - 311. En: http://www.zisonline.com/dat/artikel/2012_6_682.pdf [visitada el 22.03.2018].

SCHURMANN OPAZO, Miguel Antonio. Dogmática jurídica y racionalidad científica: análisis de los presupuestos epistémicos de las teorías dogmáticas a la luz del debate sobre la sanción de la tentativa inidónea en el derecho penal alemán. Memoria de Prueba para optar al grado de Licenciado en Ciencias Jurídicas y Sociales. Profesor guía: Antonio Bascuñán Rodríguez. Universidad de Chile. 2007.

SHAPERE, Dudley. "Significado y cambio científico", en Ian Haking, Revoluciones Científicas. Fondo de Cultura Económica. México. 1985. pp. 58 - 115.

TUGENDHAT, Ernst. Introducción a la filosofía analítica. Editorial Gedisa. 2003.

VAN WEEZEL, Alex. “¿Por qué no citamos más (por ejemplo, a los alemanes)? Réplica a J. P. Matus". En: Política Criminal, Número 6, 2008, D2-6. pp. 1-5. En http://www.politicacriminal.cl/n_06/d_2_6.pdf. [visitada el 22.03.2018].

VEGA, Jesús. "las calificaciones del saber jurídico y la pretensión de racionalidad del derecho", Doxa -Cuadernos de Filosofía del Derecho No 32, 2009. pp. 375 - 414. En http://www.cervantesvirtual.com/obra/las-calificaciones-del-saber-juridico-y-lapretension-de-racionalidad-del-derecho/ [visitada el 22.03.2018].

VERGARA BLANCO, Alejandro. "Teoría del Derecho, Filosofía del Derecho y Doctrina Jurídica", Revista de Derecho de la Pontificia Universidad Católica de Valparaíso, 2015. $\quad$ pp. $623 \quad-\quad 660 . \quad$ Disponible en: http://www.scielo.cl/scielo.php?script=sci_arttext\&pid=S071868512015000100019 [visitada el 22.03.2018].

VON WRIGHT, Georg Henrik. Explanation and Understanding. Cornell University Press. 1971. 
WILENMANN VON BERNATH, Javier. "Conocimientos especiales en la dogmática jurídico-penal y teoría de las ciencias", Revista de Estudios de la Justicia (REJ) No 13 , (2010).

pp.

135

176 ,

en:

https://revistaderechoambiental.uchile.cl/index.php/RECEJ/article/view/15247/1566 $\underline{0}$ [visitado el 22.03.2018].

WITTGENSTEIN, Ludwig. Philosophische Untersuchungen. Bibliothek Suhrkamp. 7. Edición. 2015. 